\title{
On the measurement of horizontal inequity in the delivery of health care*
}

\author{
Adam Wagstaff \\ University of Sussex, Brighton BNI $9 Q N, U K$ \\ Eddy van Doorslaer \\ Erasmus University, 3000 DR Rotterdam, Netherlands \\ Pierella Paci
}

City University, London ECIV OHB, UK

Received March 1990, final version received October 1990

This paper offers a critical appraisal of the various methods used to date to investigate inequity in the delivery of health care. It concludes that none of the methods used to date is particularly well equipped to provide unbiassed estimates of the extent of inequity. It also concludes that Le Grand's (1978) approach is likely to point towards inequity favouring the rich even when none exists. The paper offers an alternative approach, which builds on the approaches to date but seeks to overcome their deficiencies.

\section{Introduction}

Much of the empirical work on equity in the delivery of health care has been directed at the issue of horizontal equity. ${ }^{1}$ Typically this is interpreted

-This paper derives from the European Community's COMAC project on Distributive Aspects of Health Care Policies. We are grateful to the EC for financial support and to Frans Rutten - the project leader - for encouragement and advice. We are also grateful to the Centro Europa Ricerche (CER) in Rome - and in particular to Stefania Gabriele - for providing data from CER's Health Care Consumption Survey; to Ugo Ercolani of the Italian Ministry of Health and George France of the Istituto di Studi sulle Regioni for help in obtaining data on Italian health care expenditures; and to Jan van Emmerick for help in analysing data from the Dutch Health Interview Survey. We are also grateful to Guido Citoni, Julian Le Grand and an anonymous referee for helpful comments on an earlier version; the usual disclaimer applies.

${ }^{1}$ The issue of vertical equity in the delivery of health care - i.e. the issue of how those in unequal need should be treated - rarely gets discussed in the health economics literature. Cullis and West (1979, pp. 237-239) is a rare exception. Hurst (1985) claims to address the issue of vertical equity, but uses the definition of equity proposed by Aday et al. (1980), namely that equity requires that illness be the major determinant of the allocation of resources. This definition is really a definition of horizontal rather than vertical equity (cf. fn. 6). 
to mean that persons in equal need of medical care should receive the same treatment, irrespective of whether they happen to be poor or rich, old or young, black or white, and so on. ${ }^{2}$ Policy statements attach particular importance to the notion that violations of the horizontal equity principle should not be systematically related to differences in ability to pay. Thus if there are two persons in equal need of medical care, it would be considered undesirable if the richer of the two were to receive better treatment. Establishing the extent of such income-related inequity is thus accepted as one of the principal objectives of empirical research in the area.

Whilst there is broad agreement over research objectives in the field, there is less consensus over methodology. Empirical findings have therefore been the subject of some controversy. Many of these have been based on the approach proposed by Le Grand (1978) [cf. Hurst (1985), O'Donnell and Propper (1991), Wagstaff, van Doorslaer and Paci (1989)]. ${ }^{3}$ This approach has, however, been criticized by various authors, notably Collins and Klein (1980) and Puffer (1986), who have also offered alternative approaches. Though counter-attacks have been launched [cf. Le Grand (1981), Wagstaff (1989a)], these have focussed on the empirical findings of the studies to date rather than on methodological issues.

The primary purpose of this paper is to appraise the various methodologies that have been proposed to date. We suggest that none is particularly well equipped to measure income-related inequity in the delivery of health care and that most of the results reported to date should be interpreted with caution. We go on to suggest a new approach, which builds on previous approaches. This is then illustrated using microdata from Italy and the Netherlands.

\section{Previous approaches to the analysis of inequity}

Studies of horizontal inequity in the delivery of health care have typically been based on either inter-group comparisons [cf. Le Grand (1978), Collins and Klein (1980)] or regression analysis [cf. Puffer (1986)]. This section critically appraises these approaches.

\subsection{Le Grand's approach}

Le Grand (1978), in his analysis of the equity of the delivery of health care

\footnotetext{
${ }^{2}$ Other interpretations of equity in the delivery of health care do exist. The other most common definitions are equality of access and equality of health [see, e.g., Le Grand (1982), Mooney $(1983,1986)]$. The former has been the subject of very little empirical work, though the latter has been the subject of several empirical studies [see, e.g., DHSS (1980), Wilkinson (1986)]. Mooney and McGuire (1987) have argued, however, that, at least in the case of Britain, policy objectives in the field of equity seem to be defined not in terms of equality of health, but rather in terms of equal treatment for equal need and equality of access.

${ }^{3}$ O'Donnell and Propper do not rely exclusively on Le Grand's approach.
} 


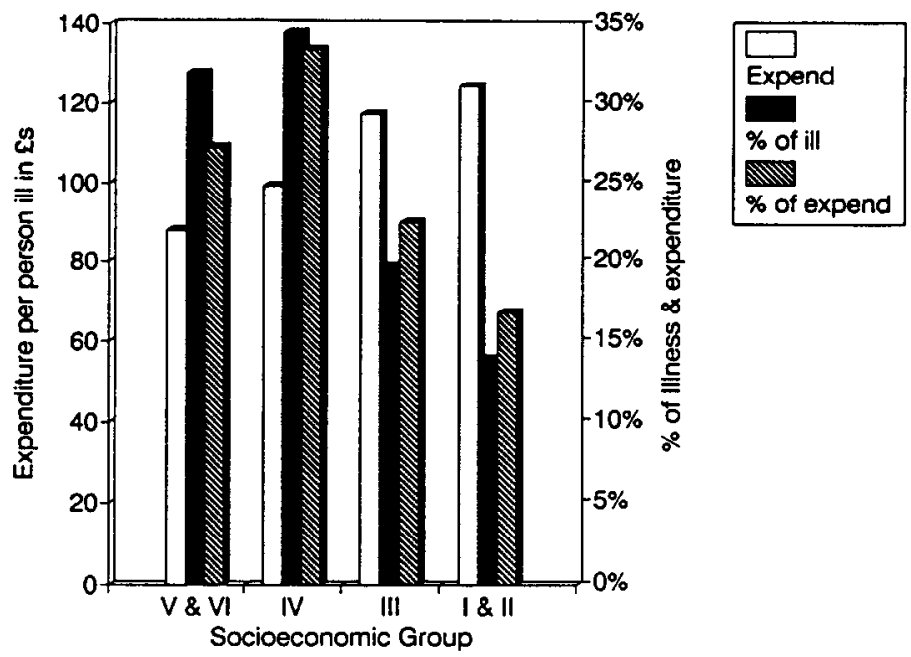

Fig. 1. Le Grand's (1978) results, England and Wales, 1972.

in the British National Health Service (NHS), performed two types of calculation. In the first he computed the cost to the NHS per person reporting illness in each socio-economic group (SEG). This is obtained by dividing each group's total imputed expenditure by the number of persons reporting either chronic or acute illness in the group. Le Grand's expenditure figures for each SEG are shown by the four lightly shaded bars in fig. 1 . The results indicate that the top two SEGs combined receive $40 \%$ more expenditure per person ill than the bottom two SEGs combined. In the second calculation Le Grand computed the share of expenditure received by each SEG and compared this with the group's share of ill-health. His results - shown by the bold and striped bars in fig. 1 - indicate that the top two SEGs combined receive $16.8 \%$ of NHS expenditure but contain only $13.9 \%$ of persons reporting ill, while the bottom two SEGs combined receive $27.3 \%$ of NHS expenditure but contain as much as $31.9 \%$ of persons reporting ill.

Le Grand concluded from both findings that the NHS has failed to achieve equal treatment for equal need [Le Grand (1982, p. 46)]. The argument is not spelt out, but seems to run something like this [cf. Wagstaff et al. $(1989$, p. 99)]. Assume that all persons reporting ill are in equal need and that only persons who are ill receive health care. Then if horizontal equity is achieved, so that those in equal need receive the same amount of public expenditure, expenditure per person reporting ill will be the same in all SEGs and the share of NHS expenditure going to each SEG will be proportional to its share of persons reporting ill. If expenditure per person reporting ill is less for the lower SEGs than for the higher SEGs, or if the 
share of NHS expenditure received by the lower SEGs is less than their share of persons reporting ill, it must be concluded that the sick in the lower SEGs receive less NHS expenditure than the sick in the higher SEGs. Equals are not being treated equally and this horizontal inequity apparently favours the rich.

\subsection{Criticisms of Le Grand's approach}

\subsubsection{Measurement of inequity}

In his attempt to give some indication of the extent of inequity Le Grand relies on comparisons between the bottom and top SEGs. Like all range measures of inequality, this approach suffers from two well-known shortcomings: it focuses exclusively on the extreme classes and fails to take into account their relative sizes.

\subsubsection{The proportionality assumption}

As indicated above, one of the assumptions implicit in Le Grand's analysis is that only persons who are ill receive treatment. Collins and Klein (1980) have questioned this. They argue that, by failing to take into account that the non-sick may also be consumers of health care, Le Grand fails to recognize that the sick and those receiving health care may not be identical populations. According to Collins and Klein, therefore, Le Grand runs the risk of committing the ecological fallacy. ${ }^{4}$

It turns out that precise predictions about the direction of bias can be made by using some simple algebra. Suppose we divide the population into two groups, rich and poor. Now consider the following model of health care consumption in which (expected) medical care consumption is proportional to health:

$$
m_{i}= \begin{cases}\beta_{\mathrm{r}} h_{i}+u_{\mathrm{ri}}, & i \in \text { rich } \\ \beta_{\mathrm{p}} h_{i}+u_{\mathrm{pi}}, & i \in \text { poor }\end{cases}
$$

where $m_{i}$ is medical care consumption, $h_{i}$ is a dummy variable taking a value of one if individual $i$ reports illness, $\beta_{\mathrm{r}}$ and $\beta_{\mathrm{p}}$ are parameters, and $u_{\mathrm{r} i}$ and $u_{\mathrm{p} i}$ are error terms. In what follows it is assumed that $E\left[u_{\mathrm{r} i}\right]=E\left[u_{\mathrm{p} i}\right]=0$. The $\beta$ 's are expected to be positive, i.e. individuals are expected to receive more medical care if they are ill than if they are well.

For this simple model, the means of the two groups' medical care utilization are given by

\footnotetext{
${ }^{4}$ Collins and Klein argue that their empirical results support this argument. For dissenting views see Le Grand (1981) and Wagstaff (1989a). For a discussion of the ecological fallacy in the context of the demand for health care, see van Vliet and van Doorslaer (1988).
} 


$$
m_{\mathrm{r}}=\beta_{\mathrm{r}} h_{\mathrm{r}}, \quad m_{\mathrm{p}}=\beta_{\mathrm{p}} h_{\mathrm{p}}
$$

where $m_{\mathrm{r}}$ is mean medical care consumption amongst the rich, $h_{\mathrm{r}}$ is mean health status of the rich, $m_{\mathrm{p}}$ is mean medical care consumption amongst the poor and $h_{\mathrm{p}}$ is mean health status of the poor. Subtracting $m_{\mathrm{p}}$ from $m_{\mathrm{r}}$, and then adding and subtracting $\beta_{\mathrm{r}} h_{\mathrm{p}}$, we get

$$
m_{\mathrm{r}}-m_{\mathrm{p}}=\beta_{\mathrm{r}} h_{\mathrm{r}}-\beta_{\mathrm{p}} h_{\mathrm{p}}=\beta_{\mathrm{r}}\left(h_{\mathrm{r}}-h_{\mathrm{p}}\right)+h_{\mathrm{p}}\left(\beta_{\mathrm{r}}-\beta_{\mathrm{p}}\right)
$$

Thus mean medical care consumption can differ between rich and poor for two reasons. First, the rich and poor do not enjoy the samc health status and therefore have different needs for medical care [the (B) term]: one would expect the poor to be, on average, in worse health than the rich and therefore $h_{\mathrm{r}}<h_{\mathrm{p}}$. Second, the slope coefficients differ [the (C) term]. The assumption implicit in Le Grand's approach is that the first term (B) does not reflect income-related inequity, or, if it does, such inequity is history. This is not true of the (C) term, which will be non-zero if persons in one group currently receive more medical care when sick than persons in the other group. In this case persons in equal need end up receiving different amounts of health care. For example, if the rich receive more medical care when ill than the poor, we have $\beta_{\mathrm{r}}>\beta_{\mathrm{p}}$ and therefore $(\mathrm{C})>0$. In general, incomerelated inequity can be said to exist in this simple model if the slope coefficients differ and therefore $(C)$ is non-zero.

It is worth noting that the definition of inequity being proposed here is similar to the traditional definition of discrimination in labour economics. There discrimination is said to occur when equally productive workers receive different levels of pay [cf., e.g., Sloane (1985, p. 85)]. Discrimination in the labour market can be on the basis of gender, race or marital status, so that in empirical work one might want to estimate the extent of, say, sex discrimination. The analysis of discrimination tends to proceed along the lines above. The sample is split according to, say, gender. Evidence of discrimination is then sought in differences in earnings functions. We return to the discrimination literature in section 2.3.4.

The presence of the (B) term above suggests that if one is trying to assess the extent of inequity by performing inter-group comparisons, one must find a way of parcelling out the inter-group differences in medical care consumption that are due to inter-group differences in health status. It thus makes little sense simply to look for differences in mean medical care expenditures between income groups. Instead one would have to adjust for differences in health status.

This is, of course, the idea behind Le Grand's two methods outlined above. 
Unfortunately, it turns out that neither is very satisfactory. For reasons of space we consider hereafter only the second. Similar results can be obtained for the first [see Wagstaff (1989b)]. For the simple model in eqs. (1) the expenditure received by the rich group is equal to

$$
\sum_{i \in \text { rich }} m_{i}=r \cdot m_{\mathrm{r}}=r \cdot \beta_{\mathrm{r}} h_{\mathrm{r}}
$$

where $r$ is the number of rich persons. Likewise the expenditure received by the poor group is equal to $p \cdot \beta_{\mathrm{p}} h_{\mathrm{p}}$, where $p$ is the number of poor persons. The share of total medical care expenditure going to the rich - denoted by $S_{\mathrm{mr}}-$ is given by

$$
S_{\mathrm{mr}}=\frac{r \cdot m_{\mathrm{r}}}{r \cdot m_{\mathrm{r}}+p \cdot m_{\mathrm{p}}}=\frac{r \cdot \beta_{\mathrm{r}} h_{\mathrm{r}}}{r \cdot \beta_{\mathrm{r}} h_{\mathrm{r}}+p \cdot \beta_{\mathrm{p}} h_{\mathrm{p}}} .
$$

The total number of rich persons reporting illness is equal to $\sum_{i \in \text { rich }} h_{i}=r \cdot h_{\mathrm{r}}$. The comparable figure for the poor is $p \cdot h_{\mathrm{p}}$. The rich group's share of ill-health is therefore given by

$$
S_{\mathrm{hr}}=\frac{r \cdot h_{\mathrm{r}}}{r \cdot h_{\mathrm{r}}+p \cdot h_{\mathrm{p}}}
$$

If there is no income-related inequity so that $\beta_{\mathrm{r}}=\beta_{\mathrm{p}}=\beta$, the rich group's share of medical care expenditures becomes

$$
S_{\mathrm{mr}}=\frac{\beta\left(r \cdot h_{\mathrm{r}}\right)}{\beta\left(r \cdot h_{\mathrm{r}}+p \cdot h_{\mathrm{p}}\right)}=S_{\mathrm{hr}}
$$

Thus if the rich group's share of medical expenditure exceeds its share of ill-health, the implication is that $\beta_{\mathrm{r}}>\beta_{\mathrm{p}}$.

The above implicitly assumes, however, that only persons reporting illness receive medical care, or equivalently (expected) medical care consumption is proportional to health, i.e. $E\left[m_{i} \mid h_{i}=0\right]=0$. If this is not the case, intercepts need to be included in the medical care equations, so that $E\left[m_{i} \mid h_{i}=0\right]$ is non-zero. In other words, one needs to recognize that under the prevailing health care delivery system the relationship between medical care and need 
may not be proportional. ${ }^{5}$ Thus suppose that the true model is linear but not proportional, ${ }^{6}$

$$
m_{i}= \begin{cases}\alpha_{\mathrm{r}}+\beta_{\mathrm{r}} h_{i}+u_{\mathrm{r} i}, & i \in \text { rich } \\ \alpha_{\mathrm{p}}+\beta_{\mathrm{p}} h_{i}+u_{\mathrm{p} i}, & i \in \text { poor }\end{cases}
$$

The means of the two groups' medical care utilization are now given by

$$
m_{\mathrm{r}}=\alpha_{\mathrm{r}}+\beta_{\mathrm{r}} h_{\mathrm{r}}, \quad m_{\mathrm{p}}=\alpha_{\mathrm{p}}+\beta_{\mathrm{p}} h_{\mathrm{p}}
$$

Subtracting $m_{\mathrm{p}}$ from $m_{\mathrm{r}}$, and then adding and subtracting $\beta_{\mathrm{r}} h_{\mathrm{p}}$, we get

$$
m_{\mathrm{r}}-m_{\mathrm{p}}=\alpha_{\mathrm{r}}-\alpha_{\mathrm{p}}+\beta_{\mathrm{r}} h_{\mathrm{r}}-\beta_{\mathrm{p}} h_{\mathrm{p}}=\left(\alpha_{\mathrm{r}}-\alpha_{\mathrm{p}}\right)+\beta_{\mathrm{r}}\left(h_{\mathrm{r}}-h_{\mathrm{p}}\right)+h_{\mathrm{p}}\left(\beta_{\mathrm{r}}-\beta_{\mathrm{p}}\right) .
$$

There is thus an additional source of difference between the two groups' means, namely that the intercepts of the medical care equations differ [the (A) term]. This also reflects income-related inequity, since even if the two groups are, on average, in equal need of medical care [i.e. (B) is zero] and the slope coefficients are identical [i.e. (C) is zero], persons in one group will, on average, receive more medical care than persons in the other. This second source of inequity ought to be reflected in any estimate of the extent of income-related inequity.

Suppose, then, that the true model is model (2). Le Grand's approach turns out to be biassed towards the detection of inequity favouring the rich. In particular we have the following result.

Proposition 1. Assume that the true model underlying the delivery of health care is as in eq. (2) and that $h_{\mathrm{p}}>h_{\mathrm{r}}$. Then it follows that $S_{\mathrm{mr}}>S_{\mathrm{hr}}$, even when the health care system is equitable.

Proof. The proof is by contradiction. Suppose that $\beta_{\mathrm{r}}=\beta_{\mathrm{p}}=\beta$ and that $\alpha_{\mathrm{r}}=\alpha_{\mathrm{p}}=\alpha$. On the definition above, therefore, there is no inequity [i.e. $(\mathrm{A})+(\mathrm{C})$ in eq. (3) is zero]. In this case the share of medical care exenditure going to the rich is

\footnotetext{
${ }^{5}$ Puffer (1986) makes essentially the same point, but appears to confuse horizontal and vertical equity. He suggests that Le Grand's approach implicitly assum(es) that a fair distribution of health care is one that is directly proportional to the measure of health status' [Puffer (1936, $p$. 296)]. Given that Le Grand's analysis relates to horizontal inequity, the question of whether or not health care ought to be distributed in proportion to need, or equivalently whether the nonsick ought to receive medical care as well as the sick, is irrelevant. This is a question of vertical rather than horizontal equity. What does matter is whether by incorrectly assuming that the non-sick do not receive medical care one runs the risk of incorrectly concluding that horizontal inequity exists.

${ }^{6}$ One could of course also explore the implications of non-linearities, though we do not do so in this paper.
} 


$$
S_{\mathrm{mr}}=\frac{\alpha \cdot r+\beta\left(r \cdot h_{\mathrm{r}}\right)}{\alpha(r+p)+\beta\left(r \cdot h_{\mathrm{r}}+p \cdot h_{\mathrm{p}}\right)}
$$

Suppose that this is less than $S_{\mathrm{hr}}$. Then we have

$$
\begin{aligned}
& \frac{r\left(\alpha+\beta_{\mathrm{hr}}\right)}{\alpha(r+p)+\beta\left(r \cdot h_{\mathrm{r}}+p \cdot h_{\mathrm{p}}\right)}<\frac{r \cdot h_{\mathrm{r}}}{t \cdot h_{\mathrm{r}}+p \cdot h_{\mathrm{p}}} \\
& \Rightarrow\left(\alpha+\beta_{\mathrm{hr}}\right)\left(r \cdot h_{\mathrm{r}}+p \cdot h_{\mathrm{p}}\right)<\left[\alpha(r+p)+\beta\left(r \cdot h_{\mathrm{r}}+p \cdot h_{\mathrm{p}}\right)\right] r \cdot h_{\mathrm{r}} \\
& \Rightarrow h_{\mathrm{p}}<h_{\mathrm{r}},
\end{aligned}
$$

which contradicts the presumption that the poor tend to be more likely to report illness than the rich.

Thus we conclude that in the case where the sick and non-sick are consumers of health care, Le Grand's approach is biassed towards the detection of inequity favouring the rich. In other words, they would suggest the existence of inequity favouring the rich even when the system is equitable. ${ }^{7}$

\subsubsection{Chronic versus acute conditions}

The second assumption implicit in Le Grand's approach is that all persons reporting illness are to be regarded as being in equal need of health care. Puffer (1986) has argued that this assumption cannot bre justified if, as in Le Grand's analysis, a person is classified as ill if he reports chronic or acute illness.

The implications of this assumption not holding can be seen as follows. Let $c_{i}$ be a dummy variable taking a value of one if individual $i$ reports chronic health problems and $s_{i}$ a dummy taking a value of one if individual $i$ reports acute sickness. Suppose the true model is now

$$
m_{i}= \begin{cases}\alpha_{\mathrm{r}}+\beta_{\mathrm{r}} c_{i}+\tau_{\mathrm{r}} s_{i}+u_{\mathrm{r} i}, & i \in \mathrm{rich} \\ \alpha_{\mathrm{p}}+\beta_{\mathrm{p}} c_{i}+\tau_{\mathrm{p}} s_{i}+u_{\mathrm{p} i}, & i \in \text { poor }\end{cases}
$$

where we expect the $\beta$ 's and the $\tau$ 's to be positive. The difference between the two income groups' mean medical care consumption can now be decomposed as

$$
m_{\mathrm{r}}-m_{\mathrm{p}}=\left(\alpha_{\mathrm{r}}-\alpha_{\mathrm{p}}\right)+\beta_{\mathrm{r}}\left(c_{\mathrm{r}}-c_{\mathrm{p}}\right)+c_{\mathrm{p}}\left(\beta_{\mathrm{r}}-\beta_{\mathrm{p}}\right)+\tau_{\mathrm{r}}\left(s_{\mathrm{r}}-s_{\mathrm{p}}\right)+s_{\mathrm{p}}\left(\tau_{\mathrm{r}}-\tau_{\mathrm{p}}\right) .
$$

(C)

(D)

${ }^{7} \mathrm{Cr}$. O'Donnell and Propper (1990) on this point. 
The (B) and (D) terms here reflect the fact that the two groups have different degrees of ill-health. The other three terms reflect income-related inequity. For this model we have the following result.

Proposition 2. Assume the model underlying the delivery of health care is as in eq. (4). Then it follows that in general $S_{\mathrm{mr}} \neq S_{\mathrm{hr}}$ even when the health care system is equitable.

Proof. The share of medical care going to the rich is given by

$$
S_{\mathrm{mr}}=\frac{r\left(\alpha_{\mathrm{r}}+\beta_{\mathrm{r}} c_{\mathrm{r}}+\tau_{\mathrm{r}} s_{\mathrm{r}}\right)}{p\left(\alpha_{\mathrm{p}}+\beta_{\mathrm{p}} c_{\mathrm{p}}+\tau_{\mathrm{p}} s_{\mathrm{p}}\right)+r\left(\alpha_{\mathrm{r}}+\beta_{\mathrm{r}} c_{\mathrm{r}}+\tau_{\mathrm{r}} s_{\mathrm{r}}\right)} .
$$

The total number of rich persons reporting either chronic or acute sickness is equal to $\sum_{i \in \text { rich }} c_{i}+\sum_{i \in \text { rich }} s_{i}$ less the number reporting both chronic and acute sickness. If one ignores this latter group, the rich group's share of ill-health is

$$
S_{\mathrm{hr}}=\frac{r\left(c_{\mathrm{r}}+s_{\mathrm{r}}\right)}{p\left(c_{\mathrm{p}}+s_{\mathrm{p}}\right)+r\left(c_{\mathrm{r}}+s_{\mathrm{r}}\right)} .
$$

Suppose there is no income-related inequity, so that $\alpha_{\mathrm{r}}=\alpha_{\mathrm{p}}=\alpha, \beta_{\mathrm{r}}=\beta_{\mathrm{p}}=\beta$ and $\tau_{\mathrm{r}}=\tau_{\mathrm{p}}=\tau$. Then

$$
S_{\mathrm{mr}}=\frac{r\left(\alpha+\beta c_{\mathrm{r}}+\tau s_{\mathrm{r}}\right)}{p\left(\alpha+\beta c_{\mathrm{p}}+\tau s_{\mathrm{p}}\right)+r\left(\alpha+\beta c_{\mathrm{r}}+\tau s_{\mathrm{r}}\right)},
$$

which will in general differ from $S_{\mathrm{hr}}$.

A sufficient condition for $S_{\mathrm{mr}}=S_{\mathrm{hr}}$ is that $\alpha=0$ and $\beta=\tau .^{8}$ The latter condition amounts to saying that acute and chronic sickness currently receive equal amounts of expenditure - a condition which seems unlikely to be satisfied. Whether, in this case, Le Grand's approach is biassed in favour of or against the detection of inequity cannot be said a priori. What can be said is the following.

Proposition 3. Assume that the true model underlying the delivery of health care is as in eq. (4). Then it follows that if $s_{\mathrm{r}} / s_{\mathrm{p}}$ is less (greater) than $c_{\mathrm{r}} / c_{\mathrm{p}}, S_{\mathrm{mr}}$ will exceed (fall short of) $S_{\mathrm{hr}}$ even if the health care system is equitable.

\footnotetext{
${ }^{8}$ Note that if one follows Le Grand's and defines the denominator as the total number reporting either chronic illness or acute sickness (i.e. with the intersection eliminated), the expenditure per person ill varies across groups when the system is equitable even when $z=0$ and $\beta=\tau$.
} 
Proof. Take the case where $S_{\mathrm{mr}}>S_{\mathrm{hr}}$. Then

$$
\begin{gathered}
\frac{r\left(\alpha+\beta c_{\mathrm{r}}+\tau s_{\mathrm{r}}\right)}{p\left(\alpha+\beta c_{\mathrm{p}}+\tau s_{\mathrm{p}}\right)+r\left(\alpha+\beta c_{\mathrm{r}}+\tau s_{\mathrm{r}}\right)}>\frac{r\left(c_{\mathrm{r}}+s_{\mathrm{r}}\right)}{p\left(c_{p}+s_{\mathrm{p}}\right)+r\left(c_{\mathrm{r}}+s_{\mathrm{r}}\right)} \\
\Rightarrow\left(\alpha+\beta c_{\mathrm{r}}+\tau s_{\mathrm{r}}\right)\left[p\left(c_{\mathrm{p}}+s_{\mathrm{p}}\right)+r\left(c_{\mathrm{r}}+s_{\mathrm{r}}\right)\right] \\
>\left(c_{\mathrm{r}}+s_{\mathrm{r}}\right)\left[p\left(\alpha+\beta c_{\mathrm{p}}+\tau s_{\mathrm{p}}\right)+r\left(\alpha+\beta c_{\mathrm{r}}+\tau s_{\mathrm{r}}\right)\right] \\
\Rightarrow \alpha\left[\left(c_{\mathrm{p}}-c_{\mathrm{r}}\right)+\left(s_{\mathrm{p}}-s_{\mathrm{r}}\right)\right]+(\tau-\beta)\left(s_{\mathrm{r}} c_{\mathrm{p}}-s_{\mathrm{p}} c_{\mathrm{r}}\right)>0 .
\end{gathered}
$$

One can safely assume that $c_{p}>c_{r}$ and $s_{p}>s_{r}$, i.e. that the poor are more likely to report chronic and acute sickness than the rich. Thus the term in square brackets on the left-hand side of the inequality above is positive. One can also probably assume that $\tau<\beta$, i.e. that the chronically sick tend to receive more resources than the acutely sick. Thus

$$
S_{\mathrm{mr}}>S_{\mathrm{hr}} \Rightarrow s_{\mathrm{r}} c_{\mathrm{p}}-s_{\mathrm{p}} c_{\mathrm{r}}<0 \Rightarrow s_{\mathrm{r}} / s_{\mathrm{p}}<c_{\mathrm{r}} / c_{\mathrm{p}}
$$

The opposite follows in the case where $S_{\mathrm{mr}}<S_{\mathrm{hr}}$.

\subsubsection{The confounding effects of demographic factors}

Le Grand $(1978,1982)$ has suggested another reason for being wary about accepting his results at face value, namely that they fail to take into account the potentially confounding influences of demographic factors. He suggests that his results 'may derive simply from differences in the age and sex composition of the groups' [Le Grand (1982, p. 26)]. Because of this he presents age-sex standardized results alongside his unstandardized results.

The rationale for standardization can be clarified as follows. Suppose that the amount of medical care a person receives depends not only on his income and health status, but also on his age. ${ }^{9}$ Thus let $x_{i}$ be a dummy variable taking a value of one if the person in question is elderly and zero otherwise. The model (2) becomes

$$
m_{i}= \begin{cases}\alpha_{\mathrm{r}}+\beta_{\mathrm{r}} h_{i}+\delta_{\mathrm{r}} x_{i}+u_{\mathrm{r} i}, & i \in \text { rich }, \\ \alpha_{\mathrm{p}}+\beta_{\mathrm{p}} h_{\mathrm{i}}+\delta_{\mathrm{p}} x_{i}+u_{\mathrm{p} i}, & i \in \text { poor }\end{cases}
$$

\footnotetext{
${ }^{9}$ That receipt of medical care depends not only on health status but also on the $x$ variable might in itself be viewed as inequitable [cf. Anderson (1976), Aday et al. (1980)]. The founding fathers of the British NHS, for example, spoke of the importance of ensuring that receipt of medical care should not depend on factors irrelevant to real need, such as age, sex, place of residence and occupation. However, this involves inequity that is related to factors other than income. Because here we focus on income-related inequity, our interest lies in the implications of a non-zero $\delta$ coefficient for measuring income-related inequity.
} 
The difference between the two income groups' mean medical care consumption can now be decomposed as

$$
m_{\mathrm{r}}-m_{\mathrm{p}}=\left(\alpha_{\mathrm{r}}-\alpha_{\mathrm{p}}\right)+\beta_{\mathrm{r}}\left(h_{\mathrm{r}}-h_{\mathrm{p}}\right)+h_{\mathrm{p}}\left(\beta_{\mathrm{r}}-\beta_{\mathrm{p}}\right)+\delta_{\mathrm{r}}\left(x_{\mathrm{r}}-x_{\mathrm{p}}\right)+x_{p}\left(\delta_{\mathrm{r}}-\delta_{\mathrm{p}}\right)
$$
(A)
(B)
(C)
(D)
(E)

The fifth term (E) reflects a further source of income-related inequity, namely that the elderly get treated differently depending on whether they are rich or poor. The fourth term (D) simply reflects the fact that the two income groups differ not only in their health status, but also in their mean ages. This has nothing to do with income-related inequity. The presence of the (D) term suggests that in order to be able to detect income-related inequity with any accuracy one must take into account not only inter-group differences in health status, but also inter-group differences in demographic characteristics, such as age. Failure to do this might result in one drawing incorrect inferences regarding the extent of income-related inequity.

In fact it turns out that when the $\delta$ 's in eq. (6) are non-zero, Le Grand's approach gives the wrong answer even if there are no differences in the age and sex composition of the two income groups.

Proposition 4. Assume that the true model underlying the delivery of health care is as in eqs. (6) except that only the sick receive treatment. Then it follows that when the health care system is equitable $S_{\mathrm{mr}}$ differs from $S_{\mathrm{hr}}$ even if the age and sex composition of the income groups are the same.

Proof. With $\alpha_{\mathrm{r}}=\alpha_{\mathrm{p}}=0, \beta_{\mathrm{r}}=\beta_{\mathrm{p}}=\beta$ and $\delta_{\mathrm{r}}=\delta_{\mathrm{p}}=\delta$ the share of medical care expenditure going to the rich is

$$
S_{\mathrm{mr}}=\frac{r \cdot \beta \cdot h_{\mathrm{r}}+r \cdot \delta \cdot x_{\mathrm{r}}}{\beta\left(r \cdot h_{\mathrm{r}}+p \cdot h_{\mathrm{p}}\right)+\delta\left(r \cdot x_{\mathrm{r}}+p \cdot x_{\mathrm{p}}\right)} .
$$

Suppose now that the two income groups have the same age structure, so that $x_{\mathrm{r}}=x_{\mathrm{p}}=x$. Then we have

$$
S_{\mathrm{mr}}=\frac{r \cdot \beta \cdot h_{\mathrm{r}}+r \cdot \delta \cdot x}{\beta\left(r \cdot h_{\mathrm{r}}+p \cdot h_{\mathrm{p}}\right)+\delta \cdot x(r+p)}
$$

which differs from $S_{\mathrm{br}}$, the rich group's share of ill-health.

A sufficient condition for Le Grand's approach to give the correct answer 
is that $x_{r} / x_{p}=h_{r} / h_{p}$. This latter condition would be met if (but not only if) the two groups had the same mean health status. This suggests that standardizing for differences in age and sex structure but not for differences in health status is unlikely to result in an unbiassed estimate of the extent of inequity.

Le Grand (1978) does, in fact, standardize for differences in both sets of variables. However, it would appear that the standardization is done in a way that biasses the result towards the detection of inequity favouring the rich. It is not clear whether the results were standardized using the direct or indirect method of standardization. ${ }^{10}$ The argument below assumes that the direct method was used, but the same conclusions are reached with the indirect method.

Suppose that the aim is to replace group means of health care consumption and health status with group means that have been standardized for age. Suppose too that only two age groups are used - old and young. Again, the conclusions would hold if one were to standardize for age and sex together, and if one were to use more age groups. The age-standardized mean medical care consumption for rich and poor are respectively

$$
m_{\mathrm{r}}^{*}=f_{\mathrm{y}} m_{\mathrm{ry}}+f_{\mathrm{o}} m_{\mathrm{ro}}, \quad m_{\mathrm{p}}^{*}=f_{\mathrm{y}} m_{\mathrm{py}}+f_{\mathrm{o}} m_{\mathrm{po}}
$$

where $f_{\mathrm{y}}$ is the proportion of the population classed as young, $f_{\mathrm{o}}$ is the proportion of the population classed as old, $\mathrm{m}_{\mathrm{ry}}$ is the mean medical care consumption in the rich-young group, and so on.

It is not obvious at first sight quite how reasonable this procedure is. Things become clearer when one realizes that this direct standardization method can be written in terms of regression equations [cf. van Vliet and van de Ven (1985)]. In Appendix A we prove the following result.

Proposition 5. The direct standardization in eq. (8) is equivalent to obtaining standardized values from the following regression equations

$$
m_{\mathrm{r}}^{*}=\Omega_{\mathrm{r}}+\Phi_{\mathrm{r}} x, \quad m_{\mathrm{p}}^{*}=\Omega_{\mathrm{p}}+\Phi_{\mathrm{p}} x
$$

where the $\Omega$ 's and $\Phi$ 's are estimates of the parameters $\Omega$ and $\Phi$, and $x$ is the

\footnotetext{
${ }^{10}$ The difference between the direct and indirect methods of standardization is most easily explained with reference to the standardization of mortality data [cf. e.g. OPCS (1973)]. In both cases the standardized figures are computed as weighted averages of age-specific death rates, where the weights correspond to either the numbers or proportions of persons falling into each of the age groups. The direct method uses the age-specific death rates for the sub-population in question but the age distribution of the population at large, while the indirect method uses the age-specific death rates for the population at large, but the age distribution of the subpopulation in question.
} 
sample mean of the age dummy $x_{i}$ (i.e. $x$ indicates the proportion of the sample who are classed as elderly).

The proof of Proposition 5 is given in Appendix A.

Thus if one can make sense of eq. (9), one can also make sense of the standardization in eq. (8). The former can, in fact, be interpreted as the reduced-form equations one obtains by substituting equations for health status into the structural equations for medical care consumption. Suppose that the true health care consumption model is as in eq. (6) and that the health of the two groups is determined according to the model

$$
h_{i}= \begin{cases}\theta_{\mathrm{r}}+\mu_{\mathrm{r}} x_{i}+e_{\mathrm{r} i}, & i \in \mathrm{rich}, \\ \theta_{\mathrm{p}}+\mu_{\mathrm{p}} x_{\mathrm{i}}+e_{\mathrm{p} i}, & i \in \text { poor }\end{cases}
$$

so that an individual's health depends on his age and income. Substituting (10) in (6) gives reduced-form equations for medical care consumption of the form

$$
m_{i}= \begin{cases}\left(\alpha_{\mathrm{r}}+\beta_{\mathrm{r}} \theta_{\mathrm{r}}\right)+\left(\beta_{\mathrm{r}} \mu_{\mathrm{r}}+\delta_{\mathrm{r}}\right) x_{i}+\left(\beta_{\mathrm{r}} e_{\mathrm{ri}}+u_{\mathrm{r} i}\right), & i \in \text { rich } \\ \left(\alpha_{\mathrm{p}}+\beta_{\mathrm{p}} \theta_{\mathrm{p}}\right)+\left(\beta_{\mathrm{p}} \mu_{\mathrm{p}}+\delta_{\mathrm{p}}\right) x_{\mathrm{i}}+\left(\beta_{\mathrm{p}} e_{\mathrm{p} i}+u_{\mathrm{p} i}\right), & i \in \text { poor }\end{cases}
$$

These are identical in form to eq. (9). In other words, eqs. (11) can be written

$$
m_{i}= \begin{cases}\Omega_{\mathrm{r}}+\Phi_{\mathrm{r}} x_{i}+u_{\mathrm{r}}^{*}, & i \in \text { rich, } \\ \Omega_{\mathrm{p}}+\Phi_{\mathrm{p}} x_{i}+u_{\mathrm{p} i}^{*}, & i \in \text { poor }\end{cases}
$$

where $\Omega_{\mathrm{r}}=\alpha_{\mathrm{r}}+\beta_{\mathrm{r}} \theta_{\mathrm{r}}, \Phi_{\mathrm{r}}=\beta_{\mathrm{r}} \mu_{\mathrm{r}}+\delta_{\mathrm{r}}, \Omega_{\mathrm{p}}=\alpha_{\mathrm{p}}+\beta_{\mathrm{p}} \theta_{\mathrm{p}}, \Phi_{\mathrm{p}}=\beta_{\mathrm{p}} \mu_{\mathrm{p}}+\delta_{\mathrm{p}}, u_{\mathrm{ri}}^{*}=\beta_{\mathrm{r}} e_{\mathrm{ri}}+u_{\mathrm{ri}}$ and $u_{\mathrm{p} i}^{*}=\beta_{\mathrm{p}} e_{\mathrm{p} i}+u_{\mathrm{p} i}$. Calculating standardized means of medical care consumption via the direct standardization method as in eq. (8) is thus equivalent to obtaining standardized means via the reduced-form regression equations in (11).

Bearing this in mind, suppose we define the rich's standardized share of medical care as

$$
S_{\mathrm{mr}}^{*}=\frac{r \cdot m_{\mathrm{r}}^{*}}{r \cdot m_{\mathrm{r}}^{*}+p \cdot m_{\mathrm{p}}^{*}}
$$

Computing the latter via the direct standardization procedure (as Le Grand does) is equivalent to obtaining it via the regression model in eq. (12). Thus

$$
\begin{aligned}
S_{\mathrm{mr}}^{*} & =\frac{r\left(\Omega_{\mathrm{r}}+\Phi_{\mathrm{r}} x\right)}{r\left(\Omega_{\mathrm{r}}+\Phi_{\mathrm{r}} x\right)+p\left(\Omega_{\mathrm{p}}+\Phi_{\mathrm{p}} x\right)} \\
& =\frac{r\left[\left(\alpha_{\mathrm{r}}+\beta_{\mathrm{r}} \theta_{\mathrm{r}}\right)+\left(\beta_{\mathrm{r}} \mu_{\mathrm{r}}+\delta_{\mathrm{r}}\right) x\right]}{\left.r\left[\left(\alpha_{\mathrm{r}}+\beta_{\mathrm{r}} \theta_{\mathrm{r}}\right)+\left(\beta_{\mathrm{r}} \mu_{\mathrm{r}}+\delta_{\mathrm{r}}\right) x\right]+p\left[\alpha_{\mathrm{p}}+\beta_{\mathrm{p}} \theta_{\mathrm{p}}\right)+\left(\beta_{\mathrm{p}} \mu_{\mathrm{r}}+\delta_{\mathrm{p}}\right) x\right]} .
\end{aligned}
$$


The rich's standardized share of ill-health is

$$
S_{\mathrm{hr}}^{*}=\frac{t \cdot h_{\mathrm{r}}^{*}}{r \cdot h_{\mathrm{r}}^{*}+p \cdot h_{\mathrm{p}}^{*}}=\frac{r\left(\theta_{\mathrm{r}}+\mu_{\mathrm{r}} x\right)}{r\left(\theta_{\mathrm{r}}+\mu_{\mathrm{r}} x\right)+p\left(\theta_{\mathrm{p}}+\mu_{\mathrm{p}} x\right)}
$$

Suppose that we are prepared to assume that $\theta_{\mathrm{r}}<\theta_{\mathrm{p}}$ (i.e. the rich have a higher autonomous level of health than the poor) and that $\mu_{\mathrm{r}}=\mu_{\mathrm{p}}=\mu$ (i.e. that differences in income merely cause shifts in the autonomous level of health, but do not alter the effect of aging on health, i.e. the $\mu$ coefficient). Then we have the following result.

Proposition 6. Assume that the true model underlying the delivery of health care is as in eq. (6), that the health of the two groups is determined according to eq. (10), that $\mu_{\mathrm{r}}=\mu_{\mathrm{p}}=\mu$ and that $\theta_{\mathrm{r}}<\theta_{\mathrm{p}}$. Then it follows that $S_{\mathrm{mr}}^{*}>S_{\mathrm{hr}}^{*}$ even when the health care system is equitable.

Proof. Again, the proof is by contradiction. If there is no inequity in the delivery of health care, $\alpha_{\mathrm{r}}=\alpha_{\mathrm{p}}=\alpha, \beta_{\mathrm{r}}=\beta_{\mathrm{p}}=\beta$ and $\delta_{\mathrm{r}}=\delta_{\mathrm{p}}=\delta$. If, in addition, $\mu_{\mathrm{r}}=\mu_{\mathrm{p}}=\mu, S_{\mathrm{mr}}^{*}$ reduces to

$$
S_{\mathrm{mr}}^{*}=\frac{\beta r\left(\theta_{r}+\mu_{\mathrm{r}} x\right)+r(x+\delta x)}{\beta\left[r\left(\theta_{\mathrm{r}}+\mu_{\mathrm{r}} x\right)+p\left(\theta_{\mathrm{p}}+\mu_{\mathrm{p}} x\right)\right]+(r+p)(x+\delta x)} .
$$

Suppose now that $S_{\mathrm{mr}}^{*}<S_{\mathrm{hr}}^{*}$. Then we have

$$
\begin{aligned}
& \frac{\beta r\left(\theta_{\mathrm{r}}+\mu_{\mathrm{r}} x\right)+r(\alpha+\delta x)}{\beta\left[r\left(\theta_{\mathrm{r}}+\mu_{\mathrm{r}} x\right)+p\left(\theta_{\mathrm{p}}+\mu_{\mathrm{p}} x\right)\right]+(r+p)(\alpha+\delta x)}<\frac{r\left(\theta_{\mathrm{r}}+\mu_{\mathrm{r}} x\right)}{r\left(\theta_{\mathrm{r}}+\mu_{\mathrm{r}} x\right)+p\left(\theta_{\mathrm{p}}+\mu_{\mathrm{p}} x\right)} \\
& \Rightarrow\left[\beta r\left(\theta_{\mathrm{r}}+\mu_{\mathrm{r}} x\right)+r(\alpha+\delta x)\right]\left[r\left(\theta_{\mathrm{r}}+\mu_{\mathrm{r}} x\right)+p\left(\theta_{\mathrm{p}}+\mu_{\mathrm{p}} x\right)\right] \\
& \quad<r\left(\theta_{\mathrm{r}}+\mu_{\mathrm{r}} x\right)\left\{\beta\left[r\left(\theta_{\mathrm{r}}+\mu_{\mathrm{r}} x\right)+p\left(\theta_{\mathrm{p}}+\mu_{\mathrm{p}} x\right)\right]+(r+p)(\alpha+\delta x)\right\} \\
& \Rightarrow \theta_{\mathrm{r}}>\theta_{\mathrm{p}},
\end{aligned}
$$

which contradicts the assumption that the rich have a higher autonomous level of health than the poor.

We conclude that Le Grand's age-sex standardized expenditure shares will suggest the existence of inequity favouring the rich even when none exists.

\subsection{Other approaches to the analysis of inequity}

To what extent do the other approaches suggested to date represent an improvement over Le Grand's approach? 


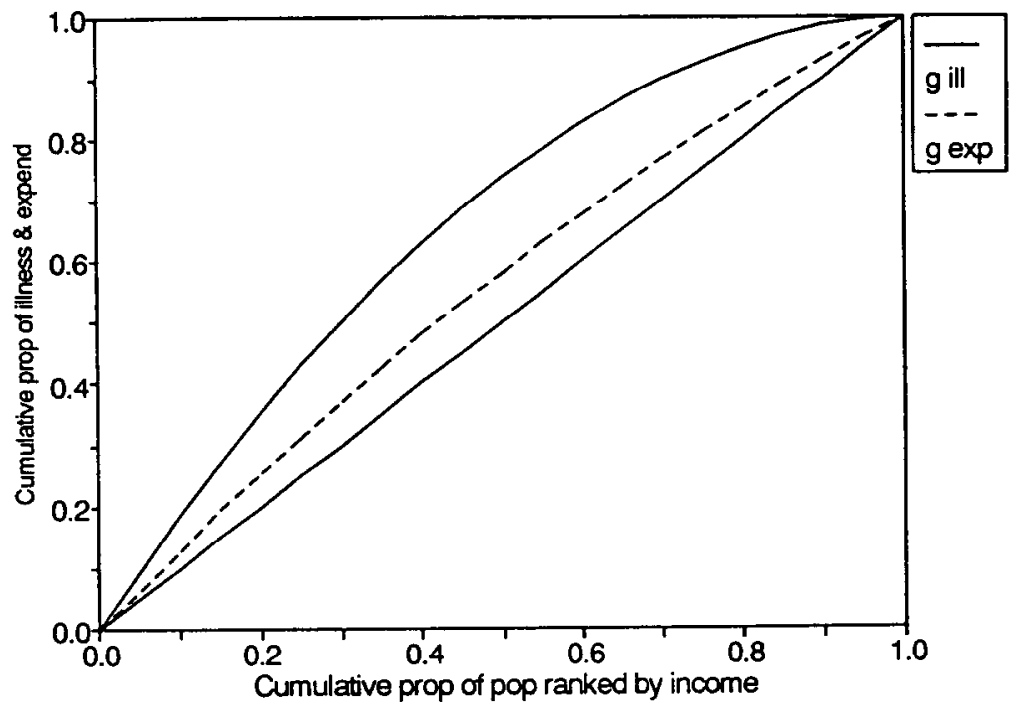

Fig. 2. Illness and expenditure concentration curves.

\subsubsection{The concentration curve approach}

Elsewhere [Wagstaff, van Doorslaer and Paci (1989)] we have suggested a way of extending Le Grand's approach to allow the extent of inequity to be quantified in a way that overcomes the limitations of Le Grand's range measures. There we rank individuals not according to their SEG but according to their income, beginning with the poorest. We then construct an illness concentration curve (the curve labelled $g_{\text {ill }}$ in fig. 2): this plots the cumulative proportions of the population (ranked by income) against the proportions of persons reporting illness. If illness is concentrated amongst the lower income groups, the illness concentration curve will lie above the diagonal, as in fig. 2. This illness concentration curve is then compared to an expenditure concentration curve. This is the curve labelled $g_{\exp }$ in fig. 2, which plots the cumulative proportions of the population against the proportions of total expenditure received. Insofar as the lower income groups are more intensive users of health services than the higher income groups, the expenditure concentration curve also lies above the diagonal. If health care expenditures are allocated across income groups in proportion to their share of total ill-health, the two concentration curves coincide. If those in lower income groups receive less medical care when ill than those in higher income groups, the expenditure concentration curve will lie below the illness concentration curve.

The extent of inequity can be assessed by looking at the size of the area between the two concentration curves. We suggested measuring the extent of 
inequity as twice this area. ${ }^{11}$ If $C_{\text {ill }}$ is the concentration coefficient for illness and $C_{\text {exp }}$ is the concentration index for expenditures, twice the area between the two concentration curves is equal to ${ }^{12}$

$$
H I_{\mathrm{LG}}=C_{\text {exp }}-C_{\mathrm{ill}} \text {, }
$$

where $H I_{\mathrm{LG}}$ is a Le Grand-type index of horizontal inequity. The index is positive if there is inequity favouring the rich and negative if there is inequity favouring the poor.

The concentration curve approach manages to overcome one of the shortcomings of Le Grand's work - the emphasis on range measures of inequality - but it does nothing to tackle the other deficiencies.

\subsubsection{The Collins-Klein approach}

Collins and Klein (1980) suggest an alternative to Le Grand's approach, which overcomes what they perceive to be the central weakness of his approach, namely that it runs the risk of committing the ecological fallacy. They divide their sample into several need categories, such as the non-sick, the acutely sick and the chronically sick. They then compare the resources received by each of the SEGs within each need category. This approach is rather more reliable than Le Grand's if, as seems to be the case, the non-sick receive medical care, and/or chronic and acute sickness receive different amounts of expenditure.

The Collins-Klein method is not, however, entirely satisfactory. To illustrate the problems with the approach, suppose the model underlying the allocation of health care is model (4). Then the mean expenditures of the chronically ill, the acutely sick and the non-sick in the rich group are, respectively,

$$
\begin{aligned}
& E\left[m_{i} \mid c_{i}=1, s_{i}=0\right]=\alpha_{\mathrm{r}}+\beta_{\mathrm{r}}, \\
& E\left[m_{i} \mid c_{i}=0, s_{i}=1\right]=\alpha_{\mathrm{r}}+\tau_{\mathrm{r}}, \\
& E\left[m_{i} \mid c_{i}=0, s_{i}=0\right]=\alpha_{\mathrm{r}},
\end{aligned}
$$

and analogously for the poor. Comparing the mean expenditures received by rich and poor within each need category gives

\footnotetext{
${ }^{11} \mathrm{Cr}$. Kakwani's (1977) index of tax progressivity.

12 Note that the concentration indices are negative if the concentration curves lie above the diagonal.
} 


\begin{tabular}{llll} 
& Chronic & Acute & Non-sick \\
\hline Rich & $\alpha_{\mathrm{r}}+\beta_{\mathrm{r}}$ & $\alpha_{\mathrm{r}}+\tau_{\mathrm{r}}$ & $\alpha_{\mathrm{r}}$ \\
Poor & $\alpha_{\mathrm{p}}+\beta_{\mathrm{p}}$ & $\alpha_{\mathrm{p}}+\tau_{\mathrm{p}}$ & $\alpha_{\mathrm{p}}$
\end{tabular}

If there is no inequity so that $\alpha_{\mathrm{r}}=\alpha_{\mathrm{p}}, \beta_{\mathrm{r}}=\beta_{\mathrm{p}}$ and $\tau_{\mathrm{r}}=\tau_{\mathrm{p}}$, the mean expenditures within each need category will be the same for both income groups.

One problem with this approach is that mean expenditures could be the same for both income groups within the chronic and acute categories even if there is inequity in the provision of health care. Thus, for example, $\alpha_{\mathrm{r}}+\beta_{\mathrm{r}}=$ $\alpha_{\mathrm{p}}+\beta_{\mathrm{p}}$ does not necessarily imply $\alpha_{\mathrm{r}}=\alpha_{\mathrm{p}}$ and $\beta_{\mathrm{r}}=\beta_{\mathrm{p}}$. It might simply be the case that $\alpha_{\mathrm{r}}>\alpha_{\mathrm{p}}$ and $\beta_{\mathrm{r}}<\beta_{\mathrm{p}}{ }^{13}$ The first implies that $(\mathrm{A})>0$ in eq. (5), while the second implies that $(C)<0$.

This points to another closely-related problem with the Collins-Klein approach, namely that it does not allow one to quantify income-related inequity. Suppose that the results suggest that $\alpha_{r}>\alpha_{p}, \beta_{r}>\beta_{p}$ and $\tau_{r}>\tau_{p}$. One might well want to know whether the degree of inequity is small or large relative to the degrec of incquity that existed beforc, or in another country. Or one might be confronted with the sort of results discussed above, where, for example, $(\mathrm{A})>0$ but $(\mathrm{C})<0$. One might want to determine whether or not on balance there is inequity favouring the rich. The Collins-Klein method does not enable one to address such issues.

\subsubsection{The regression approach}

Puffer (1986) has suggested that the assumptions of proportionality and similar treatment of the acutely and chronically sick might be relaxed by using regression analysis. He estimates an equation relating medical care consumption to measures of health status, income, age, sex and interaction terms between income and the other variables. Puffer does not rationalize his approach in terms of formal models such as those in the previous section. Indeed, he does not define inequity in terms of equal treatment for equal need, preferring instead to talk of equal access to health care. ${ }^{14} \mathrm{His}$ approach does, however, fit in naturally with the discussion above.

\footnotetext{
${ }^{13}$ The results of Collins and Klein are consistent with this. They find a class gradient in the case of the non-sick, but not in the other need categories. However, they measure $m_{i}$ not in terms of expenditure but in terms of whether or not individual $i$ had one or more GP contacts in the previous 2 weeks.

${ }^{14}$ Mooney (1983) argues that analysing access in terms of utilization of health care makes little sense if equality of access is interpreted in terms of equality of opportunity. The reason is that utilization depends not only on the opportunities available to people but also on their perceptions of the benefits to be had from health care. Instead of analysing utilization one should be analysing the time and money costs that people incur in using health care facilities [ci. Le Grand (1982)].
} 
Let $y_{i}$ be a dummy variable taking a value of 1 if person $i$ is rich and 0 otherwise. Then model (2) above can be written as

$$
m_{i}=\pi_{0}+\pi_{2} y_{i}+\pi_{2} h_{\mathrm{i}}+\pi_{3} y_{\mathrm{i}} \cdot h_{i}+u_{i},
$$

where the $\pi$ 's are coefficients. Thus we have

$$
m_{\mathrm{i}}= \begin{cases}\left(\pi_{0}+\pi_{1}\right)+\left(\pi_{2}+\pi_{3}\right) h_{i}+u_{\mathrm{ri}}, & i \in \text { rich } \\ \pi_{0}+\pi_{2} h_{i}+u_{\mathrm{p} i}, & i \in \text { poor }\end{cases}
$$

so that $\pi_{0}=\alpha_{\mathrm{p}}, \pi_{1}=\alpha_{\mathrm{r}}-\alpha_{\mathrm{p}}, \pi_{2}=\beta_{\mathrm{p}}, \pi_{3}=\beta_{\mathrm{r}}-\beta_{\mathrm{p}}$ and $u_{i}=u_{\mathrm{pi}}+y_{i} \cdot u_{\mathrm{ri}}$. If there is no income-related inequity, we have

$$
\alpha_{\mathrm{r}}=\alpha_{\mathrm{p}} \Rightarrow \pi_{1}=0, \quad \beta_{\mathrm{r}}=\beta_{\mathrm{p}} \Rightarrow \pi_{3}=0 .
$$

Thus one could estimate the parameters of the two structural equations in (2) by using a single equation regression model and then test for the existence of income-related inequity using the estimates of the $\pi \mathrm{s} .{ }^{15}$ For example, one could test the hypothesis that $\pi_{1}=0$ to test the hypothesis that the rich in the non-sick group receive more health care expenditure than their poor counterparts. Or one could test the hypothesis that $\pi_{1}=\pi_{3}=0$ to test the hypothesis that there is no income-related inequity overall: this is, in effect, what Puffer does.

One can also test the assumptions implicit in Le Grand's approach. Thus one could test the assumption that only the sick receive medical care by testing the hypothesis that $\pi_{0}+\pi_{1}=\pi_{0}=0$ (i.e. $\pi_{0}=\pi_{1}=0$ ). One can also test for the existence of inequity in model (4) where chronic and acute sickness receive different amounts of health care. In this case the model becomes

$$
m_{i}=\pi_{0}+\pi_{1} y_{i}+\pi_{2} c_{i}+\pi_{3} y_{i} \cdot c_{i}+\pi_{4} s_{i}+\pi_{5} y_{i} \cdot s_{i}+u_{i},
$$

where $\pi_{4}=\tau_{p}$ and $\pi_{s}=\tau_{r}-\tau_{p}$. If there is no inequity associated with income, we have $\pi_{1}=0$ (i.e. $\alpha_{r}=\alpha_{p}$ ), $\pi_{3}=0$ (i.e. $\beta_{r}=\beta_{p}$ ) and $\pi_{s}=0$ (i.e. $\tau_{r}=\tau_{p}$ ). One can also take into account the confounding influences of demographic factors. Thus (6) becomes

$$
m_{l}=\pi_{0}+\pi_{1} y_{i}+\pi_{2} h_{i}+\pi_{3} y_{i} \cdot h_{i}+\pi_{4} x_{i}+\pi_{5} y_{i} \cdot x_{i}+u_{i},
$$

where $\pi_{4}=\delta_{\mathrm{p}}$ and $\pi_{5}=\delta_{\mathrm{r}}-\delta_{\mathrm{p}}$. One can test the hypothesis of no inequity by testing the restriction $\pi_{1}=\pi_{3}=\pi_{5}=0$ in this more general regression equa-

\footnotetext{
${ }^{15}$ Note that eq. (13) includes the interaction term $y_{i} \cdot h_{i}$. Note too that the error term of $u_{i}$ is not homoskedastic.
} 
tion. In fact, Puffer's models are of the form of eq. (15), with gender and age included as $x$ variables. Both are allowed to interact with income, as is health status.

Instead of estimating a single equation, one could, of course, simply estimate separate equations for each income group. Irrespective of the approach adopted, one runs into the same difficulties as in the Collins-Klein method. One cannot, for example, determine whether, on balance, there is any inequity favouring the rich or not. In other words, $\pi_{1}=\pi_{2}=\pi_{3}=0$ in eq. (15) is a sufficient but not necessary condition for there to be no inequity overall. Nor does the regression approach enable inequity to be quantified.

\subsubsection{The discrimination literature}

The similarity between the concepts of inequity in the delivery of health care and discrimination in the labour market has already been noted. Given the similarity, it might be wondered whether the techniques used to measure labour market discrimination might be used to measure inequity in the delivery of health care.

The measurement of discrimination typically proceeds by decomposing wage differentials between the groups in question into two parts: a part representing the difference due to differences in characteristics, and an unexplained part which is attributed to discrimination [cf. Sloane (1985, p. 121)]. In the context of the delivery of health care eq. (7) represents such a decomposition. The terms labelled (B) and (D) represent differences in health care consumption that are attributable to differences in need and demographic factors, while the remaining terms reflect income-related inequity. Following the logic of the discrimination literature one might measure inequity as the sum of these latter terms, i.e. as $(A)+(C)+(E)$. This sum might be computed by estimating the structural model (6) either as a set of equations [cf. eq. (6)] or as a single equation model à la Puffer (1986) [cf. eq. (15)].

One problem with this approach, which also arises in the context of the discrimination literature, is the 'index number problem' [cf., e.g., Sloane (op. cit.)]. The decompositions in eqs. (3), (5) and (7) are arbitrary in the sense that they are based implicitly on the rich group's utilization equation rather than the poor group's equation. Take the case of model (2). Denote by $m_{\tilde{p}}$ the mean medical care consumption the poor would have received if they had received medical care, not according to their own utilization equation, but according to the rich group's equation. We might call this the poor group's expected mean consumption. Thus $m_{\mathrm{p}}$ is is equal to

$$
m_{\mathrm{p}}=\alpha_{\mathrm{r}}+\beta_{\mathrm{r}} h_{\mathrm{p}} .
$$


Then the difference between actual mean medical care consumption of the rich and poor can be decomposed as

$$
\begin{aligned}
m_{\mathrm{r}}-m_{\mathrm{p}} & =\left[m_{\mathrm{r}}-m_{\mathrm{p}}^{\tilde{p}}\right]+\left[m_{\mathrm{p}}^{\tilde{y}}-m_{\mathrm{p}}\right] \\
& =\alpha_{\mathrm{r}}+\beta_{\mathrm{r}} h_{\mathrm{r}}-\alpha_{\mathrm{r}}-\beta_{\mathrm{r}} h_{\mathrm{p}}+\alpha_{\mathrm{r}}+\beta_{\mathrm{r}} h_{\mathrm{p}}-\alpha_{\mathrm{p}}+\beta_{\mathrm{p}} h_{\mathrm{p}} \\
& =\left(\alpha_{\mathrm{r}}-\alpha_{\mathrm{p}}\right)+\beta_{\mathrm{r}}\left(h_{\mathrm{r}}-h_{\mathrm{r}}\right)+h_{\mathrm{p}}\left(\beta_{\mathrm{r}}-\beta_{\mathrm{p}}\right),
\end{aligned}
$$

$\begin{array}{lll}\text { (A) } & \text { (B) }\end{array}$

which is what we had in eq. (3). Now suppose that instead of using the poor group's expected medical care consumption in the decomposition, we were to use the rich group's expected consumption evaluated with respect to the poor group's utilization equation. The latter is equal to

$$
m_{\mathrm{r}}=\alpha_{\mathrm{p}}+\beta_{\mathrm{p}} h_{\mathrm{r}}
$$

The difference between actual mean medical care consumption of the rich and poor can now be decomposed as

$$
\begin{aligned}
m_{\mathrm{r}}-m_{\mathrm{p}} & =\left[m_{\mathrm{r}}-m_{\mathrm{r}}^{2}\right]+\left[m_{\mathrm{r}}^{2}-m_{\mathrm{p}}\right] \\
& =x_{\mathrm{r}}+\beta_{\mathrm{r}} h_{\mathrm{r}}-\alpha_{\mathrm{p}}-\beta_{\mathrm{p}} h_{\mathrm{r}}+\alpha_{\mathrm{p}}+\beta_{\mathrm{p}} h_{\mathrm{r}}-\alpha_{\mathrm{p}}+\beta_{\mathrm{p}} h_{\mathrm{p}} \\
& =\left(\alpha_{\mathrm{r}}-\alpha_{\mathrm{p}}\right)+\beta_{\mathrm{r}}\left(h_{\mathrm{r}}-h_{\mathrm{p}}\right)+h_{\mathrm{r}}\left(\beta_{\mathrm{r}}-\beta_{\mathrm{p}}\right),
\end{aligned}
$$

(A) (B) $\quad$ (C)

This approach thus yields a similar but not identical decomposition. In the initial case, where the decomposition was implicitly with reference to the rich group's utilization equation, the difference between the two groups' slope coefficients was weighted by $h_{\mathrm{p}}$. In the second case, where the decomposition is implicitly with reference to the poor group's utilization equation, the difference between the two groups' slope coefficients is weighted by $h_{\mathrm{r}}$. Since it is unlikely that $h_{\mathrm{r}}$ and $h_{\mathrm{p}}$ are the same, the estimated overall degree of inequity will differ, depending on which decomposition one uses.

There is another problem with the above approach, namely that it relies on there being two, and only two, naturally defined sub-populations. In the context of discrimination this dichotomy is not a major problem, since the population divides naturally into sub-populations thought to be treated differently. Obvious examples include males and females, and blacks and whites. In the present context no such natural divisions arise. The distinction between rich and poor throughout the discussion above has been for 
illustrative purposes only, and even then there is no natural line dividing rich and poor. In the present context, therefore, the approach used in the measurement of labour market discrimination would not appear to be an attractive option.

\section{A new approach to the measurement of inequity}

In the previous section it was argued that Le Grand's approach provides a biassed picture of the degree of inequity in the delivery of health care. The shortcomings of the approach include (i) a failure to allow for the possibility that the non-sick may be consumers of health care as well as the sick, (ii) a failure to allow for the possibility that the chronically and acutely sick may, under the current health care delivery system, receive different amounts of health care, and (iii) the use of an inappropriate procedure for standardizing for demographic factors. By contrast the approaches of Collins and Klein (1980) and Puffer (1986) do not suffer from these shortcomings. Neither, however, provides a measure of the extent of inequity. This section outlines a new approach to the analysis of inequity, which builds on Le Grand's approach but also makes use of the regression approach.

Assume for the moment that the true model is as in eq. (4). This is not a key assumption: indeed, it is possible in principle to base one's analysis on any model of health care utilization. We define new standardized values $m_{r}^{+}$ and $m_{\mathrm{p}}^{+}$as

$$
\begin{aligned}
& m_{\mathrm{r}}^{+}=\alpha_{\mathrm{r}}+\beta_{\mathrm{r}} h+\delta_{\mathrm{r}} x, \\
& m_{\mathrm{p}}^{+}=\alpha_{\mathrm{p}}+\beta_{\mathrm{p}} h+\delta_{\mathrm{p}} x,
\end{aligned}
$$

where $h$ and $x$ are the sample means of $h_{i}$ and $x_{i}$ respectively. Note that these standardized values are obtained from the structural model [cf. eq. (6)] and not from the reduced-form model [cf. eq. (11)]. It is this that distinguishes the present standardization method from Le Grand's.

Armed with these standardized values one can go on to compute standardized expenditure shares and then building on the approach of Wagstaff et al. (1989). Consider again the model in eq. (6). Now define the rich group's standardized expenditure share as

$$
S_{\mathrm{mr}}^{+}=\frac{r \cdot m_{\mathrm{r}}^{+}}{r \cdot m_{\mathrm{r}}^{+}+p \cdot m_{\mathrm{p}}^{+}}=\frac{r\left(\alpha_{\mathrm{r}}+\beta_{\mathrm{r}} h+\delta_{\mathrm{r}} x\right)}{p\left(\alpha_{\mathrm{p}}+\beta_{\mathrm{p}} h+\delta_{\mathrm{p}} x\right)+r\left(\alpha_{\mathrm{r}}+\beta_{\mathrm{r}} h+\delta_{\mathrm{r}} x\right)},
$$

and analogously for the poor. If there is no income-related inequity, $\alpha_{\mathrm{p}}=\alpha_{\mathrm{r}}=\alpha, \beta_{\mathrm{r}}=\beta_{\mathrm{p}}=\beta$ and $\delta_{\mathrm{r}}=\delta_{\mathrm{p}}=\delta$. In this case $S_{\mathrm{mr}}^{+}$becomes 


$$
S_{\mathrm{mr}}^{+}=\frac{r}{(r+p)} \cdot \frac{(\alpha+\beta h+\delta x)}{(\alpha+\beta h+\delta x)}=\frac{r}{(r+p)}
$$

and analogously for the poor. Thus if there is no inequity, each income group's standardized expenditure share is equal to its share in the population. On the other hand, if, on balance, there is inequity favouring the rich, the rich group's standardized expenditure share exceeds its share in the population and the poor group's standardized expenditure share falls short of its population share. More precisely, we have the following result.

Proposition 7. If the standardized medical expenditure share of the rich, $S_{\mathrm{mr}}^{+}$, exceeds its population share, $r /(r+p)$, it follows that

$$
\left(\alpha_{\mathrm{r}}-\alpha_{\mathrm{p}}\right)+h\left(\beta_{\mathrm{r}}-\beta_{\mathrm{p}}\right)+x\left(\delta_{\mathrm{r}}-\delta_{\mathrm{p}}\right)>0
$$

The opposite is true of the poor.

Proof. Suppose that $S_{\mathrm{mr}}^{+}>r /(r+p)$. Then

$$
\begin{aligned}
& \frac{r\left(\alpha_{\mathrm{r}}+\beta_{\mathrm{r}} h+\delta_{\mathrm{r}} x\right)}{p\left(\alpha_{\mathrm{p}}+\beta_{\mathrm{p}} h+\delta_{\mathrm{p}} x\right)+r\left(\alpha_{\mathrm{r}}+\beta_{\mathrm{r}} h+\delta_{\mathrm{r}} x\right)}>\frac{r}{r+p} \\
& \Rightarrow(r+p)\left(x_{\mathrm{r}}+\beta_{\mathrm{r}} h+\delta_{\mathrm{r}} x\right)>p\left(\alpha_{\mathrm{p}}+\beta_{\mathrm{p}} h+\delta_{\mathrm{p}} x\right)+r\left(\alpha_{\mathrm{r}}+\beta_{\mathrm{r}} h+\delta_{\mathrm{r}} x\right) \\
& \Rightarrow\left(\alpha_{\mathrm{r}}-\alpha_{\mathrm{p}}\right)+h\left(\beta_{\mathrm{r}}-\beta_{\mathrm{p}}\right)+x\left(\delta_{\mathrm{r}}-\delta_{\mathrm{p}}\right)>0 .
\end{aligned}
$$

The proof for the poor follows the same lines.

Contrast this result with that obtained for Le Grand's standardization procedure (Proposition 6). There it was found that with even when no inequity exists $S_{\mathrm{mr}}^{*}>S_{\mathrm{hr}}^{*}$. Note too that the first term on the left-hand side of (18) is term (A) in the decomposition in eq. (7). The second and third terms are similar to terms (C) and (E) in eq. (7). However, they weight the differences in slope coefficients by the relevant sample means rather than by the means of the poor group [cf. the decomposition in eq. (7)]. This implies that the degree of inequity affecting a given illness category is weighted by the fraction of the population in that category: the entire population is affected by any differences in the $\alpha$ 's; only the sick (a fraction $h$ of the population) are affected by a discrepancy in the $\beta$ 's; and only the elderly (a fraction $x$ of the population) are affected by a discrepancy in the $\delta$ 's. This would appear to be a natural solution to the 'index number' problem which 
has plagued the discrimination literature. It would seem not unreasonable therefore to say that there is inequity favouring the rich if the sum of the three terms on the left-hand side of (18) is positive. On this definition, then, $S_{\mathrm{mr}}^{+}>S_{\mathrm{hr}}^{+}$implies that there is inequity favouring the rich.

In contrast to Le Grand's approach, then, the approach above presents an unbiassed picture of the degree of inequity, assuming, of course, that the model is specified correctly. Moreover, it can easily be generalized. There is no reason why, for example, chronic and acute health indicators should not be included separately in the structural model [cf. eq. (6)]. The model could also be generalized to allow for more than two income groups, and the inclusion of demographic (and non-demographic) factors other than age. Moreover, if the structural model is of a similar form to eq. (16), there is no reason why the standardized values should not be obtained via the direct standardization procedure rather than via regression analysis. ${ }^{16}$ In the case of eq. (16) we have the following result.

Proposition 8. The direct standardization analogues of eq. (16) are given by

$$
\begin{aligned}
& m_{\mathrm{r}}^{+}=f_{\mathrm{hy}} m_{\mathrm{rhy}}+f_{\mathrm{sy}} m_{\mathrm{rsy}}+f_{\mathrm{ho}} m_{\mathrm{rho}}+f_{\mathrm{so}} m_{\mathrm{rso}} \\
& m_{\mathrm{p}}^{+}=f_{\mathrm{hy}} m_{\mathrm{phy}}+f_{\mathrm{sy}} m_{\mathrm{psy}}+f_{\mathrm{ho}} m_{\mathrm{pho}}+f_{\mathrm{so}} m_{\mathrm{pso}}
\end{aligned}
$$

where $f_{\mathrm{hy}}$ is the proportion of the population classed as both healthy and young, $f_{\mathrm{sy}}$ is the proportion of the population classed as sick and young, $f_{\text {ho }}$ is the proportion of the population classed as healthy and old, $f_{\mathrm{so}}$ is the proportion of the population classed as sick and old, $m_{\mathrm{rhy}}$ is the mean medical care consumption amongst persons who are rich, healthy and young, and so on.

The proof of Proposition 8 is given in Appendix A.

The standardized shares approach can easily be extended to more than two income groups. Using the resultant standardized expenditure shares for the various income groups one can then plot a standardized expenditure concentration curve. This is the curve labelled $g_{\exp }^{+}$in fig. 3 and plots the cumulative proportions of the population - again ranked according to income - against their standardized shares of expenditure received. If there is inequity favouring the rich, $g_{\exp }^{+}$will lie below the diagonal (the case illustrated in fig. 3), whilst the opposite will be true if there is inequity favouring the poor. The extent of inequity can be measured by the concentration index for the standardized concentration curve, $g_{\text {exp }}^{+}$. Thus an alternative index of inequity to $H I_{\mathrm{LG}}$ is

\footnotetext{
${ }^{16}$ Whilst all direct standardizations can be written in the form of a regression model, the converse is not true.
} 


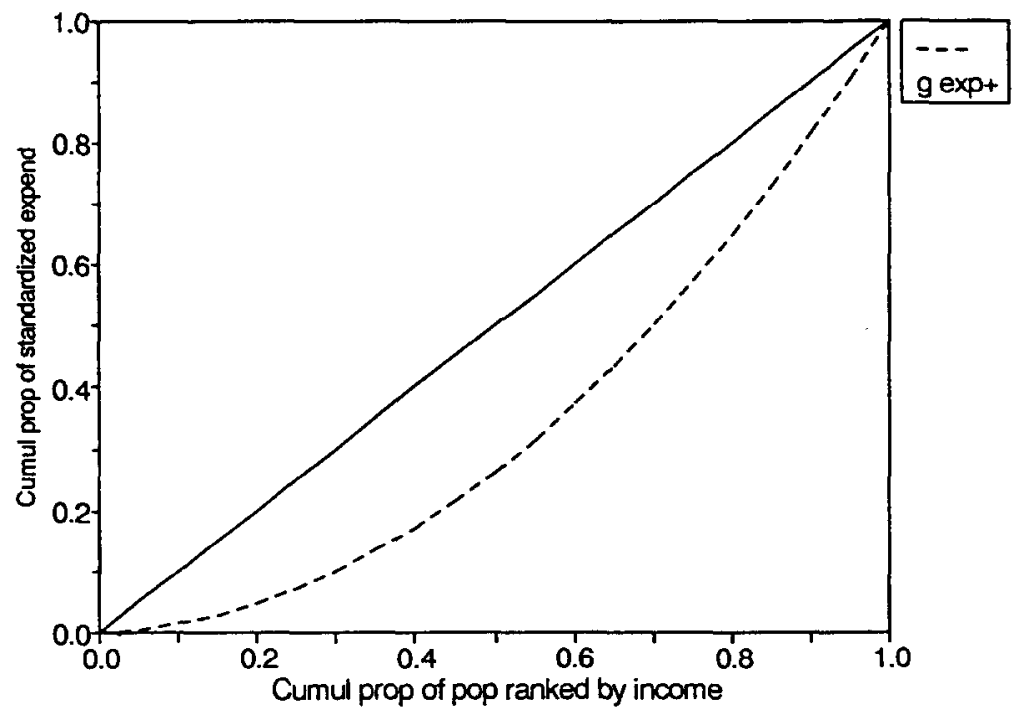

Fig. 3. Standardized expenditure concentration curve.

$$
H I_{\mathrm{WVP}}=C_{\text {exp }}^{+} \text {, }
$$

where $C_{\text {exp }}^{+}$is the concentration index corresponding to $g_{\text {exp }}^{+}$. In the case illustrated, $H I_{\mathrm{WVP}}$ is defined as the ellipse-shaped area between $g_{\text {exp }}^{+}$and the diagonal, expressed as a proportion of the area under the diagonal. In the case where $g_{\exp }^{+}$lies above the diagonal (i.e. where there is inequity favouring the poor), the concentration index is defined as the negative of the ellipseshaped area as a proportion of the area under the diagonal. Thus, $H I_{\text {wvp }}$ is negative when there is inequity favouring the poor (the lower bound being $-1)$, zero when there is no inequity, and positive when there is inequity favouring the rich (the upper bound being +1 ).

\section{Some illustrative cross-country comparisons}

In this section we present some empirical illustrations of the approach suggested in section 3 using data for Italy and the Netherlands.

\subsection{Results for Italy}

Our data for Italy are taken from the 1985 Health Care Consumption Survey conducted by Centro Europa Richerche (CER) - a private research institute. ${ }^{17}$ This survey, in contrast to the health survey undertaken by the

${ }^{17}$ See Bariletti et al. (1986) for an overview of the survey. 
Italian government's Central Institute of Statistics (ISTAT), ${ }^{18}$ contains information on income, albeit in a rather crude form. The survey's primary drawback is that the sample is not representative of the Italian population. In particular it overrepresents the under-60s and underrepresents the over$60 \mathrm{~s}$. We therefore weighted the sample so as to make it more representative. ${ }^{19}$

Our measure of income is pre-tax family income. We were unable to convert family income to a per-person or per-equivalent-adult basis, in part because we do not have the actual figure for income (individuals are allocated to one of five income groups) ${ }^{20}$ and in part because we do not have information on the structure of the respondent's family. Individuals are classified as ill if they reported their health as being not 'good'. Health care expenditure was estimated using information on the number of GP visits in the last three months, the number of specialist consultations in the same period, and the number of spells in hospital in the last year. ${ }^{21}$ The latter were divided by 4 to convert them to a quarterly basis. GP and specialist consultations were then weighted by the relevant cost per consultation in the public sector in 1985, whilst hospital spells were weighted by the cost per case in 1985 in non-profit hospitals providing care to the state under contract (so-called ospedali convenzionati). ${ }^{22}$ The unit costs were calculated at Lit 24,851 , Lit 50,690, and Lit 4,001,375 respectively. ${ }^{23}$

Fig. 4 indicates the distribution of illness and health care expenditure in Italy across five income groups. The results are similar to those obtained by Le Grand (1978) for England and Wales in fig. 1. The bottom income group (which comprises $22.4 \%$ of the sample) includes as much $37 \%$ of the sick, but receives only $27.8 \%$ of health care expenditure. By contrast the top income group (which comprises $20.4 \%$ of the sample) includes only $14.7 \%$ of the sick, but receives as much as $19.9 \%$ of health care expenditure. The values of the $C_{\text {ill }}, C_{\text {exp }}$ aand $H I_{\mathrm{LG}}$ indices are $-0.1665,-0.0510$, and 0.1155 respectively (cf. fig. 12). ${ }^{24}$ The fact that $H I_{\mathrm{LG}}$ is positive indicates that there is inequity

\footnotetext{
${ }^{18}$ See, e.g., ISTAT $(1986,1987)$.

${ }^{19}$ Details of the weighting are to be found in Paci and Wagstaff (1989). The replication of Le Grand's analysis reported in Wagstaff et al. (1989) was based on an unweighted sample. The results are therefore different from those reported below.

${ }^{20}$ The data set contains two variables on income, one containing 10 categories, the other containing 4. In neither case is the sample evenly spread across the categories, so we have generated a new 5-category variable based approximately on quintiles. The exact distribution of the sample across the 5 categories is indicated in fig. 4.

${ }^{21}$ In the results for Italy presented in Wagstaff et al. (1989) we did not distinguish between GP and specialist consultations.

${ }^{22}$ There are no published or unpublished data on the expenditure associated with public sector hospitals in Italy. Nor were we able to obtain data on the costs of private hospitals.

${ }^{23}$ Full details of the cost calculations in the present paper are reported in Paci and Wagstaff (1989).

${ }^{24}$ The concentration indices were calculated by means of linear approximation [cf. Fuller and Lury $(1977$, p. 68)].
} 

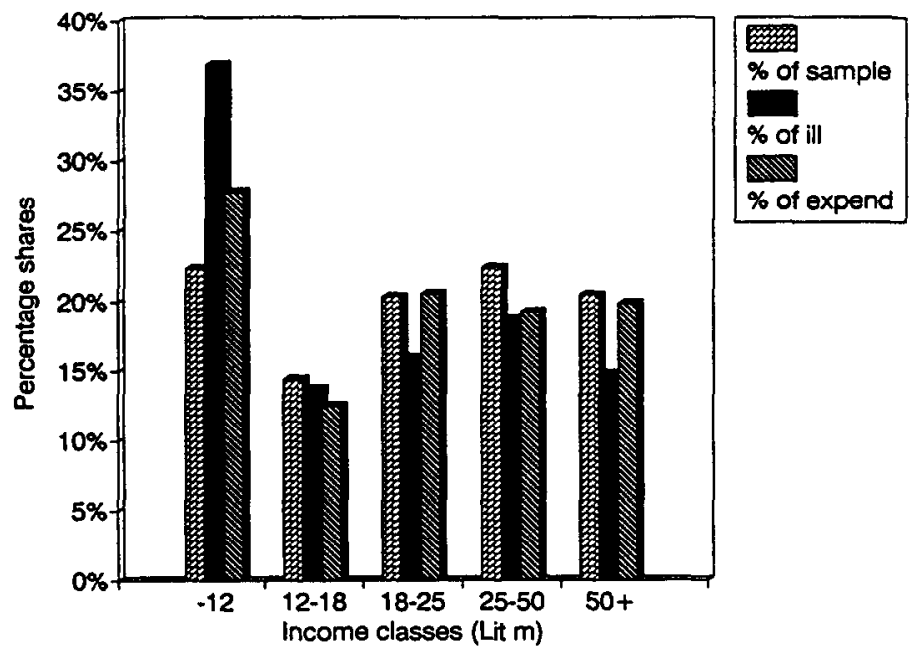

Fig. 4. Expenditure and illness shares, Italy 1985.

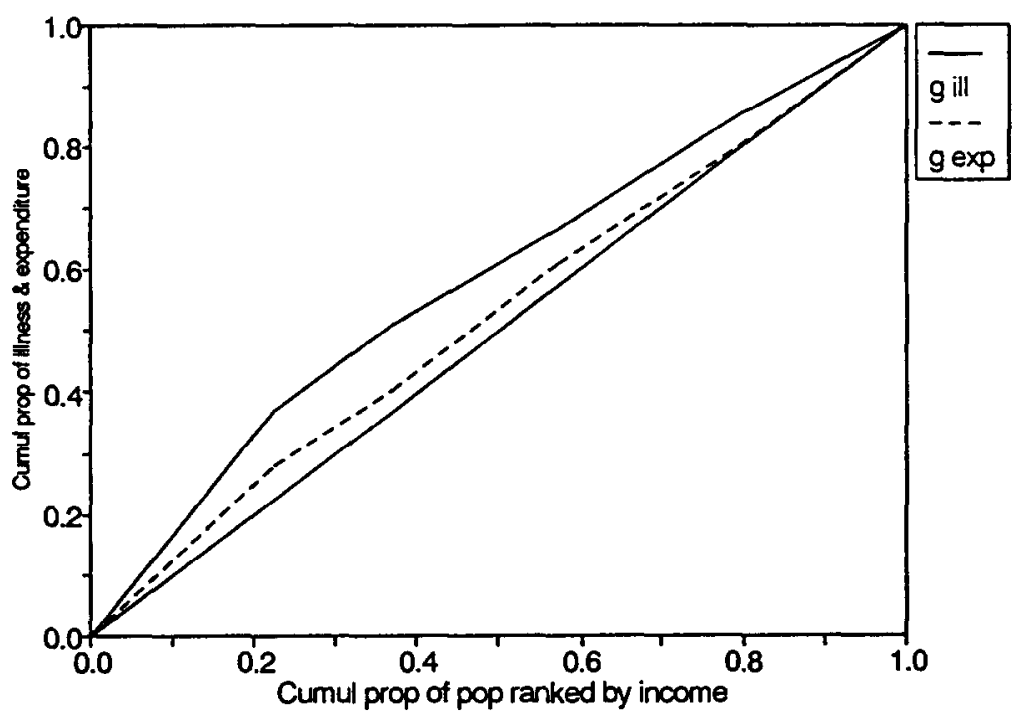

Fig. 5. Illness and expenditure concentration curves, Italy 1985.

favouring the rich. The concentration curves $g_{\text {ill }}$ and $g_{\exp }$ are shown in fig. 5: the latter lies everywhere below the former, indicating that the inequity is apparently unambiguous.

Fig. 6 shows the standardized expenditure shares using the method 


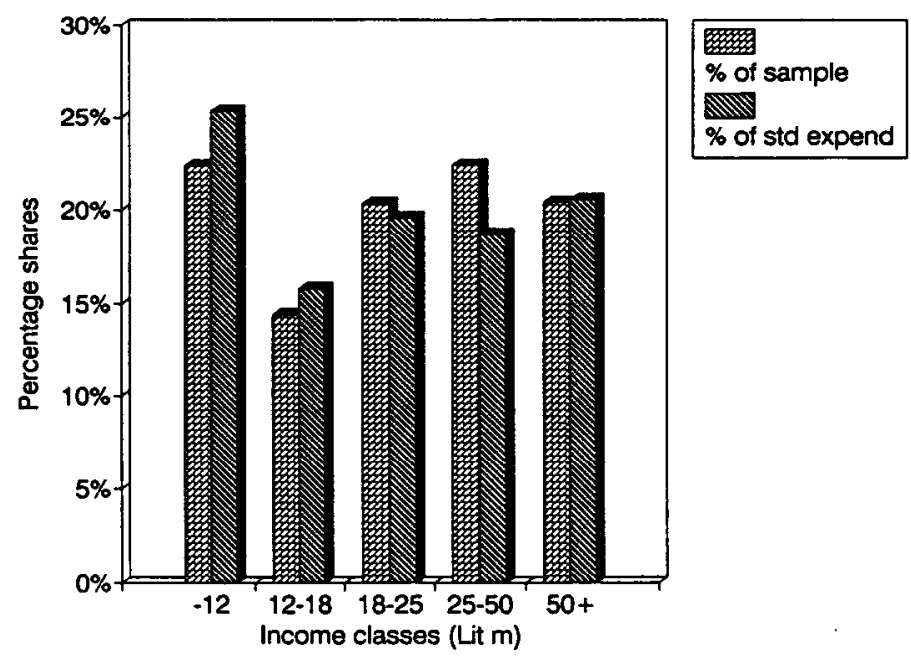

Fig. 6. Standardized expenditure shares, Italy 1985.

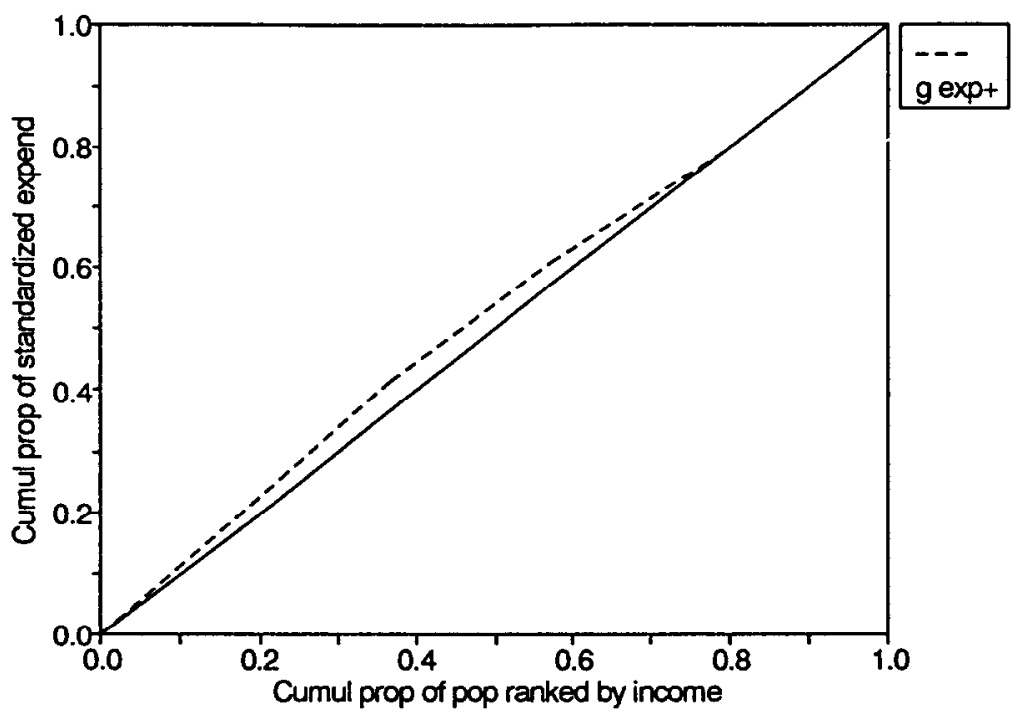

Fig. 7. Standard expenditure concentration curve, Italy. 
outlined in section 3. We standardized for illness, age and sex, using four age categories, namely (i) 18-29, (ii) 30-44, (iii) $45-59$ and (iv) $60+$. The standardized shares were calculated via the direct standardization method using the following equation:

$$
m_{k}^{+}=\sum_{i=1} \sum_{j=1} \sum_{p=1} f_{l j p} m_{k l j p}, \quad k=1,2, \ldots, 5
$$

where $f_{l j p}$ denotes the proportion of the population classified in gender group $l$, age group $j$ and health category $p$, and $m_{k l j p}$ is mean health care consumption of persons in the $k$ th income group who are classified in gender group $l$, age group $j$ and health category $p .^{25}$ From the relative standardized expenditure shares in fig 6 one can obtain cumulative standardized shares which can be used to construct the standardized concentration curve, $g_{\text {exp }}^{+}$In this case the curve - shown in fig. 7 - actually lies above the diagonal for the bottom four income groups and below the diagonal thereafter. The value of $H I_{\mathrm{WvP}}$ is -0.0409 (cf. fig. 12), which indicates that, on balance, any inequity favours the poor rather than the rich. This result is consistent with Proposition 1, in which it was suggested that Le Grand's method overstates the degree of inequity favouring the rich.

\subsection{Results for the Netherlands}

Our data for the Netherlands are taken from the combined 1981 and 1982 Health Interview Surveys conducted by the Dutch government's Central Bureau of Statistics (CBS). Our measure of income is pre-tax family income. To permit comparisons with the Italian results in section 4.1 we left income on a per-family basis rather than convert it to a per-equivalent-adult basis. As in the analysis for Italy, individuals were classified as ill if they reported their health as being not 'good'. Health care expenditure was estimated using information on the number of GP visits in the previous three months, the number of specalist visits in the previous three months, and the number of days in hospital in the last year. The latter was divided by 4 to convert it to a quarterly basis. Each category of expenditure was then weighted by the relcvant unit cost for the public sector in 1981/82. The unit costs were calculated at Dfl 27.00 , Dfl 75.00 , and Dfl 45.80 , respectively. ${ }^{26}$

Fig. 8 indicates the distribution of illness and health care expenditure in the Netherlands across five income groups. The results are similar to those in figs. 1 and 4. The bottom income group in the Netherlands (which comprises $21 \%$ of the sample) includes as much as $31.2 \%$ of the sick, but receives only

\footnotetext{
${ }^{25}$ Due to the relatively small sample size, 4 of the 80 cells were empty. In these cases we used the means for all income groups.

${ }^{26}$ Details of the cost calculations are to be found in Van Doorslaer and Wagstaff (1989).
} 


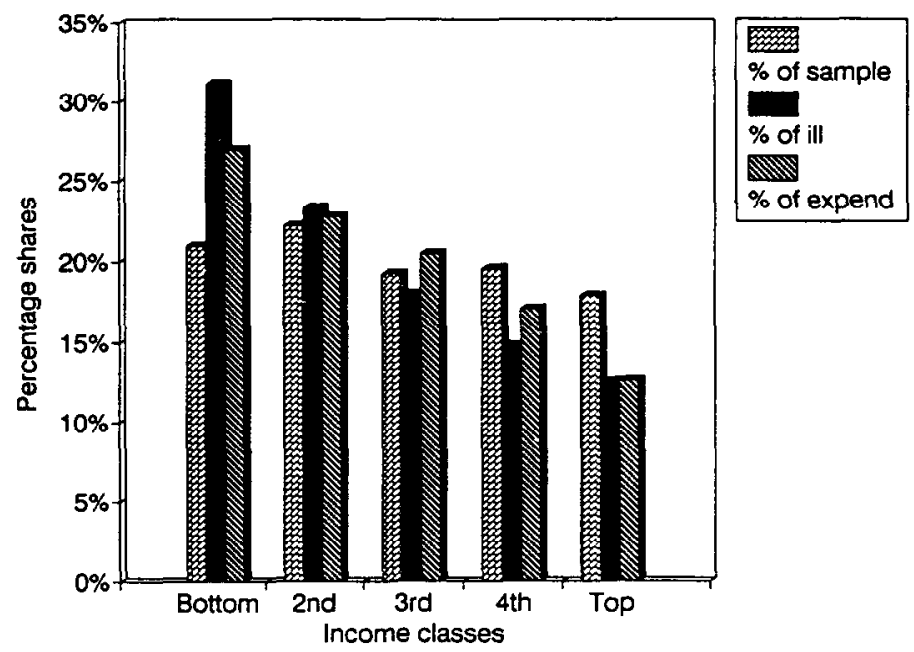

Fig. 8. Expenditure and illness shares, Netherlands 1981-1982.

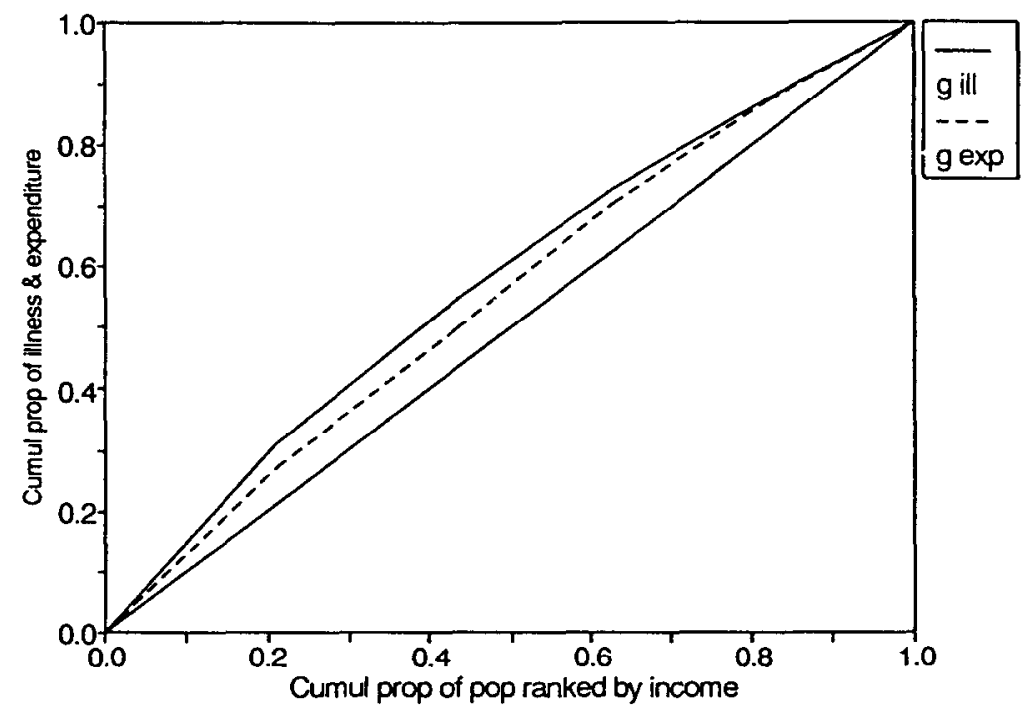

Fig. 9. Illness and expenditure concentration curves, Netherlands 1981-1982. 
$27 \%$ of health care expenditure. The values of the $C_{\mathrm{ill}}, C_{\exp }$ and the $H I_{\mathrm{LG}}$ indices are equal to $-0.1508,-0.1302$, and 0.0476 respectively. The latter indicates the existence of inequality favouring the rich. As was the case with the Italian sample, the expenditure concentration curve lies everywhere below the illness concentration curve (cf. fig. 9). The value of the $H I_{\mathrm{LG}}$ index for the Netherlands is, however, much smaller than that of Italy (cf. fig. 12). The reason for this is that although inequalities in health are similar in the two countries (the values of $C_{\text {in }}$ are very similar), the distribution of health care reflects the distribution of health less in Italy than in the Netherlands.

Fig. 10 shows the standardized expenditure shares for the Netherlands after standardization along the lines suggested in section 3. We standardized for illness, age and sex, using four age categories, namely (i) 18-34, (ii) 35-44, (iii) 45-64 and (iv) 65+. The standardized shares were calculated via the direct standardization method using eq. (20). The standardized concentration curve, $g_{\text {exp }}^{+}$, is shown in fig. 11: it lies below the diagonal for the two bottom income groups and above the diagonal thereafter. The value of $H I_{\mathrm{wVP}}$ is -0.0080 (cf. fig. 12), which indicates that, on balance, any inequity favours the poor rather than the rich. As before the relative magnitudes of $H I_{\text {WVP }}$ and $H I_{\mathrm{LG}}$ are consistent with Proposition 1. The value of the former is, however, very small in absolute value in the Dutch case. Interestingly, it is also smaller in absolute value than the value of $H I_{\mathrm{WvP}}$ for Italy, suggesting that there is less inequity favouring the poor.

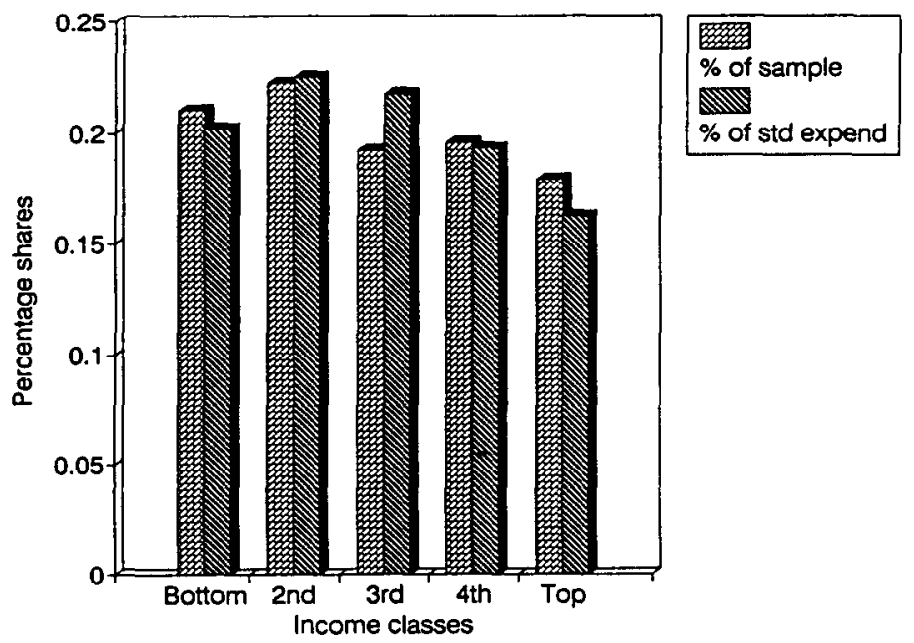

Fig. 10. Standardized expenditure shares, Netherlands 1981-1982. 


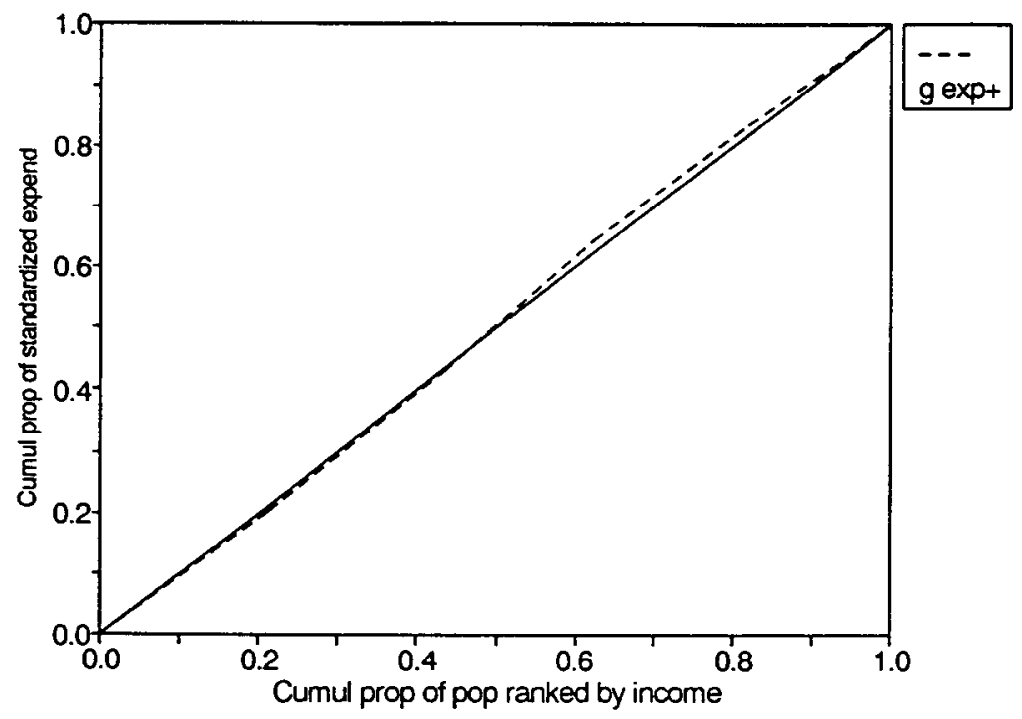

Fig. 11. Standardized expenditure concentration curve, Netherlands 1981.

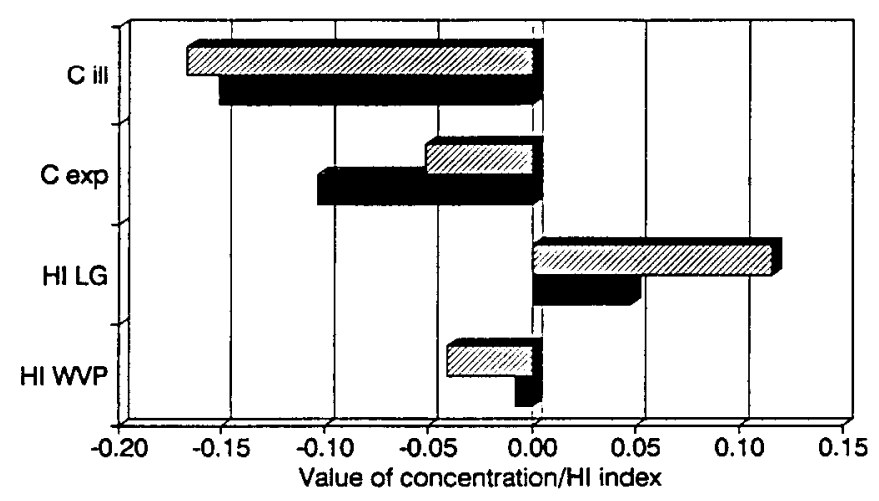

Netherlands Italy

Fig. 12. Summary of empirical results.

\section{Summary and discussion}

Most of the empirical work on equity in the delivery of health care has been based on the concept of horizontal equity. Tyically this is interpreted to mean that persons in equal need of health care should receive equal amounts of health care, irrespective of whether they happen to be rich or poor. The aim of empirical work in the area has thus been to establish the extent to which violations of the principle of horizontal inequity are related to income. 
Much of this empirical work has been based on the methodology proposed by Le Grand (1978) in which the distribution of health care expenditures across socioeconomic groups is compared with the distribution of illness across these groups. Le Grand's work has, however, been criticized on several counts. First, in seeking to quantify the extent of inequity le Grand relies on simple range measures of inequality. Second, by implicitly assuming that the sick and consumers of health care are the same population, Le Grand - it is argued - commits the ecological fallacy [Collins and Klein (1980)]. We showed above that this biasses the results towards detection of inequity favouring the rich. Third, Le Grand's implicit assumption that the chronically and acutely sick are equally ill has been questioned [Puffer (1986)] and we have shown that this too produces a bias in le Grand's approach, but that the direction of bias cannot be established a priori. Finally, Le Grand's attempts to take into account the effects of demographic factors appear to be less than satisfactory: indeed, it appears that his methods will tend to point towards inequity favouring the rich, even when none exists.

Attempts to improve on Le Grand's approach have been only partially successful. Elsewhere [Wagstaff, van Doorslaer and Paci (1989)] we have suggested how Le Grand's approach might be extended to permit the quantification of inequity in a way that avoids the shortcomings of Le Grand's range measures. This extension does nothing, however, to remedy the other defects of his approach. Collins and Klein (1980) propose analysing different need categories separately. This avoids the ecological fallacy and allows the acutely and chronically sick to receive different amounts of care. The approach does not, however, allow inequity to be quantified. The same is true of Puffer's (1986) regression approach.

We have suggested an alternative approach to the measurement of inequity that builds on the previous approaches. This involves constructing expenditure shares which are standardized in such a way as to ensure that each income group's expenditure share will be equal to its population share under an equitable health care delivery system. The concentration index corresponding to the standardized expenditure shares is used as a measure of inequity. Illustrative empirical results for Italy and the Netherlands lend support to the idea that Le Grand's method overstates the degree of inequity favouring the rich. In both countries Le Grand's method points towards inequity in favour of the rich, whilst the method based on standardized concentration curves suggests the existence of inequity favouring the poor.

It is only fair to note that whilst the concentration curve approach suggested in the paper would appear to overcome the shortcomings of Le Grand's earlier work, it too entails assumptions which may not command universal assent. First, since we have attempted to measure global inequity (i.e. inequity within several need categories simultaneously), we have had to make a judgement about how to weight each group's inequity. In the $H I_{\text {WVP }}$ 
index proposed above inequity affecting a given illness category is weighted by the fraction of the population in that category. This seems to be a reasonable starting point, but it may well be the case that policy-makers might wish later to adopt an alternative value judgement. Second, in our identification of $H I_{\text {WvP }}$ with $C_{\text {exp }}^{+}$we have implicitly assumed that when $g_{\text {exp }}^{+}$ crosses the diagonal (as it does in both our empirical illustrations), any inequity favouring the poor can be offset against any inequity favouring the rich, and vice versa. It might be argued (though we are not inclined to such a view) that whether inequity favours the rich or poor is immaterial: what matters is that violations of the principle of equal treatment for equal need should not be related to income. If this argument is accepted, horizontal inequity might be measured as the absolute value of any deviations of $g_{\exp }^{+}$ from the diagonal. Finally, like standard concentration indices (of which the Gini coefficient is a special case), the $H I_{\mathrm{WvP}}$ index implicitly entails an assumption about the weight to be attached to inequity at different income levels. ${ }^{27}$ This is important in cases such as in section 4 where the $g_{\text {exp }}^{+}$curve of one country crosses that of another ( $\mathrm{cf}$. figs 7 and 11). In such cases one cannot appeal to the concept of 'Lorenz dominance', and the concentration index is acceptable as a tie-breaker only to the extent that the implicit weighting scheme used in its construction is acceptable. ${ }^{28}$ Clearly it may be desirable in future work to explore the possibility of making such judgements explicit via a social welfare function [cf., e.g., Atkinson (1970)].

\section{Appendix A}

Proof of Proposition 5. The proof is a special case of the results reported in van Vliet and van de Ven (1985). Take the case of the rich group. Suppose the rich receive health care according to the equation

$$
m_{i}=\Omega_{\mathrm{r}}+\Phi_{\mathrm{r}} x_{i}+u_{\mathrm{ri}}^{*}, \quad i \in \mathrm{rich}
$$

where $u_{r i}^{*}$ is an error term. First define $m_{i}^{*}$ as the medical care consumption individual $i$ would have received if he had received medical care according to the rich group's utilization equation. Thus, $m_{i}^{*}$ is equal to

$$
m_{i}^{*}=\Omega_{\mathrm{r}}+\Phi_{\mathrm{r}} x_{i}
$$

Next define $m_{\mathrm{r}}^{*}$ as the average medical care consumption that would have been recorded for the population at large if all persons in the population had received medical care according to the rich group's utilization equation. Thus $m_{\mathrm{r}}^{*}$ is equal to

\footnotetext{
${ }^{27}$ For an excellent discussion of the value judgements implicit in the Gini coefficient, see Deaton and Muellbauer (1950).

${ }^{28}$ We are grateful to an anonymous referee for his remarks on this point.
} 


$$
\begin{aligned}
m_{\mathrm{r}}^{*} & =(1 / n) \sum_{i \in \text { pop }} m_{i}^{*} \\
& =(1 / n) \sum_{i \in \text { pop }}\left(\Omega_{\mathrm{r}}+\Phi_{\mathrm{r}} x_{i}\right) \\
& =\Omega_{\mathrm{r}}+\frac{\Phi_{\mathrm{r}}}{n} \sum_{i \in \text { pop }} x_{i} \\
& =\Omega_{\mathrm{r}}+\Phi_{\mathrm{r}} x
\end{aligned}
$$

which is the first equation in (9). It remains to show that this is equivalent to the first equation in (8). The model contains two parameters, $\Omega_{\varepsilon}$ and $\Phi_{r}$, the OLS estimators of which are given by

$$
\Omega_{\mathrm{r}}=m_{\mathrm{ry}}, \quad \Phi_{\mathrm{r}}=m_{\mathrm{ro}}-m_{\mathrm{ry}} .
$$

This can be seen intuitively by taking expected values for the two subgroups, i.e.

$$
\begin{aligned}
& E\left[m_{i} \mid i \in \text { rich, } x_{i}=0\right]=\Omega_{\mathrm{r}}=m_{\mathrm{ry}}, \\
& E\left[m_{i} \mid i \in \text { rich, } x_{i}=1\right]=\Omega_{\mathrm{r}}+\Phi_{\mathrm{r}}=m_{\mathrm{ro}}
\end{aligned}
$$

Substituting these into the equation

$$
m_{r}^{*}=\Omega_{r}+\Phi_{r} x
$$

yields

$$
m_{\mathrm{r}}^{*}=m_{\mathrm{ry}}+\left(m_{\mathrm{ro}}-m_{\mathrm{ry}}\right) x=m_{\mathrm{ry}}(1-x)+m_{\mathrm{ro}} x .
$$

But $x$ (the sample mean of $x_{i}$ ) is simply the proportion of the population classified as old. Thus $x=f_{0}$ and therefore $(1-x)=f_{y}$. Substituting these expressions in the above gives

$$
m_{\mathrm{r}}^{*}=f_{\mathrm{y}} m_{\mathrm{ry}}+f_{\mathrm{o}} m_{\mathrm{ro}}
$$

which is the desired result. Exactly the same argument applies to $m_{\mathrm{p}}^{*}$.

Proof of Proposition 8. The proof is similar to the proof of Proposition 5. Take the case of the rich group. Suppose the rich receive health care according to the equation 


$$
m_{\mathrm{i}}=\alpha_{\mathrm{r}}+\beta_{\mathrm{r}} h_{i}+\delta_{\mathrm{r}} x_{i}+u_{\mathrm{r} i}, \quad i \in \mathrm{rich}
$$

which, following the logic of Proposition 3, gives

$$
m_{\mathrm{r}}^{+}=\alpha_{\mathrm{r}}+\beta_{\mathrm{r}} h+\delta_{\mathrm{r}} x
$$

In this model there are, in effect, four parameters, namely the expected values for the four sub-groups. These are

$$
\begin{aligned}
& E\left[m_{i} \mid i \in \text { rich }, h_{i}=0, x_{i}=0\right]=\alpha_{\mathrm{r}}=m_{\mathrm{rhy}}, \\
& E\left[m_{i} \mid i \in \text { rich }, h_{i}=1, x_{i}=0\right]=\alpha_{\mathrm{r}}+\beta_{\mathrm{r}}=m_{\mathrm{rsy}}, \\
& E\left[m_{i} \mid i \in \text { rich }, h_{i}=0, x_{i}=1\right]=\alpha_{\mathrm{r}}+\delta_{\mathrm{r}}=m_{\mathrm{rho}}, \\
& E\left[m_{i} \mid i \in \text { rich }, h_{i}=1, x_{i}=1\right]=\alpha_{\mathrm{r}}+\beta_{\mathrm{r}}+\delta_{\mathrm{r}}=m_{\mathrm{rso}} .
\end{aligned}
$$

Thus (A.1) is equivalent to the model

$$
m_{i}=\sum_{j} \phi_{j i} z_{j i}+u_{\mathrm{ri}}, \quad i \in \mathrm{rich}
$$

where

$$
\begin{aligned}
& z_{1 i}=1 \quad \text { if } h_{i}=0 \text { and } x_{i}=0, \\
& z_{2 i}=1 \quad \text { if } h_{i}=1 \text { and } x_{i}=0 \\
& z_{3 i}=1 \quad \text { if } h_{i}=0 \text { and } x_{i}=1 \\
& z_{4 i}=1 \quad \text { if } h_{i}=0 \text { and } x_{i}=1
\end{aligned}
$$

From (A.3) one gets an alternative expression for $m_{r}^{+}$, namely

$$
m_{r}^{+}=\sum_{j} \phi_{j r} z_{j}
$$

where the $z_{j}$ are the sample means of the $z_{j i}$. The OLS estimators of the $\phi_{j r}$ are given by

$$
\begin{aligned}
& \phi_{1 \mathrm{r}}=m_{\mathrm{rhy}}=\alpha_{\mathrm{r}}, \\
& \phi_{2 \mathrm{r}}=m_{\mathrm{rsy}}=\alpha_{\mathrm{r}}+\beta_{\mathrm{r}}, \\
& \phi_{3 \mathrm{r}}=m_{\mathrm{rho}}=\alpha_{\mathrm{r}}+\delta_{\mathrm{r}}, \\
& \phi_{4 \mathrm{r}}=m_{\mathrm{rso}}=\alpha_{\mathrm{r}}+\beta_{\mathrm{r}}+\delta_{\mathrm{r}} .
\end{aligned}
$$


That (A.2) and (A.4) are equivalent can be seen by using eqs. (A.5) and (A.4) to get

$$
\begin{aligned}
m_{\mathrm{r}}^{+} & =\alpha_{\mathrm{r}} z_{1}+\left(\alpha_{\mathrm{r}}+\beta_{\mathrm{r}}\right) z_{2}+\left(\alpha_{\mathrm{r}}+\delta_{\mathrm{r}}\right) z_{3}+\left(\alpha_{\mathrm{r}}+\beta_{\mathrm{r}}+\delta_{\mathrm{r}}\right) z_{4} \\
& =\alpha_{\mathrm{r}}\left(z_{1}+z_{2}+z_{3}+z_{4}\right)+\beta_{\mathrm{r}}\left(z_{2}+z_{4}\right)+\delta_{\mathrm{r}}\left(z_{3}+z_{4}\right) .
\end{aligned}
$$

But $z_{1}+z_{2}+z_{3}+z_{4}=1, z_{2}+z_{4}=h$ and $z_{3}+z_{4}=x$. Substituting these expressions in the equation above gives (A.2). It remains to establish the equivalence of (A.4) and the first of the equations in eq. (17). This can be done by using eqs. (A.5) and (A.4) to get

$$
m_{\mathrm{r}}^{+}=m_{\mathrm{rhy}} z_{1}+m_{\mathrm{rsy}} z_{2}+m_{\mathrm{rho}} z_{3}+m_{\mathrm{rso}} z_{4} .
$$

But $z_{1}=f_{\mathrm{hy}}, z_{2}=f_{\mathrm{sy}}, z_{3}=f_{\mathrm{ho}}$ and $z_{4}=f_{\mathrm{so}}$. Substituting these expressions in the equation above gives

$$
m_{\mathrm{r}}^{+}=f_{\mathrm{hy}} m_{\mathrm{rhy}}+f_{\mathrm{sy}} m_{\mathrm{rsy}}+f_{\mathrm{ho}} \mathrm{m}_{\mathrm{rho}}+f_{\mathrm{so}} m_{\mathrm{rso}},
$$

which is the first of eq. (19) in the text. Exactly the same argument applies to $m_{\mathbf{p}}^{+}$.

\section{References}

Aday, L.A., R. Andersen and G.Y. Flemming, 1980, Health care in the U.S.: Equitable for whom? (Sage, Beverley Hills, CA).

Andersen, R., 1975, Health service distribution and equity, in: R. Anderson et al., eds., Equity in health services (Ballinger, Cambridge, MA).

Atkinson, A.B., 1970, On the measurement of inequality, Journal of Economic Theory 2, 244-263.

Bariletti, A., S. Gabriele, M. Marè and D. Piacentino, 1986, Indagine sui consumi sanitari delle famiglie Italiane, Research Report, Centro Europa Richerche, Rome.

Collins, E. and R. Klein, 1980, Equity and the NHS: Self-reported morbidity, access and primary care, British Medical Journal 281, 1111-1115.

Cullis, J.G. and P.A. West, 1979, The economics of health: An introduction (Martin Robertson, Oxford).

Deaton, A. and J. Muellbauer, 1980, Economics and consumer behavior (Cambridge University Press, Cambridge).

Department of Health and Social Security, 1980, The Black report: Report of a working group on inequalities in health (DHSS, London).

Fuller, M.F. and D.A. Lury, 1977, Statistics workbook for social science students (Philip Allan, Oxford).

Hurst, J., 1985, Financing health care in the U.S., Canada and Britain (Kings Fund, London).

Istituto Centrale di Statistica (ISTAT), 1986, Indagine statistica sulle condizioni di salute della popolazione e sul ricorso ai servizi sanitari Novembre 1983, Note e Relazioni no. 1, Istituto Centrale di Statistica, Rome.

Istituto Centrale di Statistica (ISTAT), 1987, Indagine statistica sulle condizioni di salute della popolazione e sul ricorso ai servizi sanitari Novembre 1986-Aprile 1987: Primi resultati, Notiziario Serie 4 Foglio 41, Istituto Centrale di Statistica, Rome. 
Kakwani, N.C., 1977, Measurement of tax progressivity: An international comparison, Economic Journal 87, 71-80.

Le Grand, J., 1978, The distribution of public expenditure: The case of health care, Economica $45,125-142$.

Le Grand, J., 1981, Letter to the editor, British Medical Journal 283, 147.

Le Grand, J., 1982, The strategy of equality (Allen \& Unwin, London).

Mooney, G., 1983, Equity in health care: Confronting the confusion, Effective Health Care 1, 179-185.

Mooney, G., 1986, Economics, medicine and health care (Wheatsheaf, Brighton).

Mooney, G. and A. McGuire, 1987, Distributive justice with special reference to geographical inequality in health care, in: A. Williams, ed., Health and economics (Macmillan, London).

O'Donnell, O. and C. Propper, 1991, Equity and the distribution of U.K. National Health Service resources, Journal of Health Economics 10, no. 1, 1-19.

Office of Population, Censuses and Statistics, 1973, Occupational morality: Decennial supplement 1970-1972 (HMSO, London).

Paci, P. and A. Wagstaff, 1989, Inequity in the delivery of health care in Italy: Preliminary empirical results, EC Cost Containment Project Working paper no. 9 (Limburg University, Maastricht.

Puffer, F., 1986, Access to primary care: A comparison of the U.S. and U.K., Journal of Social Policy 15, 293-313.

Sloane, P.J., 1985, Discrimination in the labour market, in: D. Carline et al., Labour economics (Longman, London).

Van Doorslaer, E. and A. Wagstaff, 1989, Inequity in the delivery of health care in the Netherlands: Preliminary empirical results and guidelines for participants in the EC study on cost containment, EC Cost Containment Project Working paper no. 3 (Limburg University, Maastricht).

Van Vliet, R. and W. Van de Ven, 1985, Differences in medical consumption between publicly and privately insured in the Netherlands: Standardization by means of multiple regression. Paper presented to International Meeting on Health Econometrics of the Applied Econometric Association, December 16-17, Rotterdam.

Van Vliet, R. and E. Van Doorslaer, 1988, Disaggregation of the demand for hospital care, Applied Economics 20, 969-984.

Wagstaff, A., 1989a, Econometric studies in health economics: A survey of the British literature, Journal of Health Economics 8, 1-51.

Wagstaff, A., 1989b, Measuring equity in the delivery of health care, EC Cost Containment Project Working paper no. 2 (Limburg University, Maastricht).

Wagstaff, A., E. Van Doorslaer and P. Paci, 1989, Equity in the finance and delivery of health care: Some tentative cross-country comparisons, Oxford Review of Economic Policy 5, no. 1, $89-112$.

Wilkinson, R., ed., 1986, Class and health (Tavistock, London). 